\title{
A QUESTÃO DA SEPARABILIDADE FRACA NA ESTIMAÇÃO DE SISTEMAS DE DEMANDA: UMA APLICAÇÃO PARA A DEMANDA DE CARNES NO BRASIL
}

\author{
Guilherme Fonseca Travassos * \\ Alexandre Bragança Coelho ${ }^{\dagger}$
}

\begin{abstract}
Resumo
A separabilidade fraca das preferências é uma hipótese frequentemente mantida, porém pouco testada em análises de demanda aplicada. Este estudo buscou testar essa hipótese em um sistema de demanda por carnes no Brasil, utilizando os microdados da POF 2008-09. Concluiu-se que os consumidores não separam carnes por tipo de animal ou por qualidade da carne e que uma estimação de demanda de carnes sem utilizar preço e dispêndio com outros alimentos incorre em omissão de variáveis relevantes, influenciando nas estimativas das elasticidades-preço cruzadas.
\end{abstract}

Palavras-chave: Separabilidade fraca; demanda por carnes; POF 2008-09

\begin{abstract}
Weak separability is a frequently maintained hypothesis in demand analysis and it's rarely tested. This paper tested the restrictions of weak separability in a meat demand system in Brazil, using microdata from POF 2008-09. Results showed that consumers do not distinguish meats by animal type or quality and that an estimate of demand for meats without using price and expenditure of other foods incurs in omission of relevant variables, impacting cross price elasticities.
\end{abstract}

Keywords: Weak separability; demand for meat; POF 2008-09.

JEL classification: D11, D12, C21

DOI: http://dx.doi.org/10.1590/1413-8050/ea 135987

\footnotetext{
* Doutorando em Economia Aplicada - Universidade Federal de Viçosa. Email: travassosgf@hotmail.com

${ }^{\dagger}$ Professor Associado no Departamento de Economia Rural - Universidade Federal de Viçosa. Email: acoelho@ufv.br
} 


\section{Introdução}

O conceito de separabilidade fraca, originalmente introduzido por Leontief (1947) e posteriormente por Sono (1961), é extremamente útil para a análise de sistemas de demanda devido a suas implicações em relação à coerência na agregação de bens e na descentralização das decisões de otimização da utilidade (Blackorby et al. 1978). Entretanto, a separabilidade fraca das preferências é uma hipótese frequentemente mantida, porém pouco testada em análises de demanda aplicada.

De acordo com Deaton \& Muellbauer (1980), inicialmente é preciso entender quando as preferências por si próprias podem ou não proporcionar uma estrutura natural de demanda por bens. A primeira ideia referente a isso seria a de separabilidade de preferências. Se isso for possível, um grupo de bens pode ser particionado de modo que as preferências dentro dos subgrupos oriundos dessa partição possam ser descritos independentemente das quantidades do grupo inicial. Isso implica que é possível se obter funções de utilidade para cada subgrupo, e então, os valores destes combinados proverão a utilidade total do grupo. Por exemplo, a utilidade das carnes de boi, frango e porco, combinados, proporcionariam a utilidade do grupo carnes. Ainda, pode-se inferir que não existe nenhum motivo para que cada bem de um determinado grupo não possa originar mais produtos, por exemplo, dentro do grupo carnes, tem-se a carne de frango que pode ser dividida em partes processadas e o frango inteiro. Se analisadas todas essas implicações de maneira conjunta, por exemplo, para o grupo Carnes, seria possível visualizar a árvore de utilidades do grupo.

É nesse contexto que o conceito de separabilidade fraca é extremamente útil para o entendimento. De acordo com Blackorby et al. (1978), o significado econômico da introdução do conceito de separabilidade é que as decisões dos consumidores passam a ser feitas em estágios. Em primeiro lugar, os consumidores maximizam suas funções utilidade alocando sua renda entre grupos de produtos (por exemplo, carnes, cereais, verduras, etc.). Num segundo estágio, o orçamento de cada grupo seria alocado entre os bens dentro dos grupos (por exemplo, no grupo carnes, carne bovina, de frango, suína etc.). Ainda, dentro do grupo carnes, pode-se analisar um terceiro estágio, que seria a alocação de recursos entre os bens dentro dos subgrupos (por exemplo, no subgrupo carne de frango têm-se partes processadas do frango e o frango inteiro). Entretanto, de acordo com Deaton \& Muellbauer (1980), separabilidade fraca e divisão de orçamento em estágios são intimamente relacionadas, mas não equivalentes, não sendo verdade que uma implica a outra. Pode-se dizer, então, que a separabilidade fraca é condição necessária e suficiente para a existência do último estágio de escolha do consumidor e para utilização de preços e dispêndio na estimação da demanda apenas desse estágio ${ }^{1}$.

As condições para os outros estágios (que não o último), que envolvem a alocação do gasto total em grupos amplos, é mais problemática (Deaton \& $\mathrm{Mu}$ ellbauer 1980). Uma solução exata requer condições pouco plausíveis, como

\footnotetext{
${ }^{1}$ As condições para os outros estágios (que não o último), que envolvem a alocação do gasto total em grupos amplos, é mais problemática (Deaton \& Muellbauer 1980). Uma solução exata requer condições pouco plausíveis, como homoteticidade ou aditividade entre as utilidades dos grupos. Geralmente, utiliza-se uma solução aproximada, com a utilização de índices de preço do tipo Laspeyres para os grupos. Para maiores detalhes, ver Deaton \& Muellbauer (1980, p. 122-133).
} 
homoteticidade ou aditividade entre as utilidades dos grupos. Geralmente, utiliza-se uma solução aproximada, com a utilização de índices de preço do tipo Laspeyres para os grupos. Para maiores detalhes, ver Deaton \& Muellbauer (1980, p. 122-133). ${ }^{2}$ Finalmente, do ponto de vista empírico, a separabilidade fraca reduz significativamente o número de parâmetros do sistema de demanda a ser estimado, que podem ser recuperados posteriormente (Deaton \& Muellbauer 1980).

Além disso, há implicações práticas da violação da hipótese mantida de Separabilidade. Pode-se destacar, por exemplo, como a hipótese de Separabilidade é importante nos testes de mudança ou quebra estrutural nos padrões de demanda, como destacado por Eales \& Unnevehr (1988). Neste trabalho, os autores investigaram a mudança na demanda norte-americana de carnes, especialmente a maior preferência por carne de frango em detrimento da carne bovina. Seus resultados mostraram que a estimação de sistemas de demanda por carnes de forma agregada enviesou os testes para a quebra estrutural. Os testes de Separabilidade e a correta especificação da árvore de utilidade permitiram concluir que o aumento na taxa de crescimento da demanda agregada por frango nos EUA após 1974 foi devido à maior participação das partes processadas de frango no agregado Frango, chamado pelos autores de maior demanda por conveniência, ao invés de um aumento na taxa de mudança de preferencias (maior demanda devido a preocupações com a saúde) como outros estudos que não consideraram a Separabilidade haviam concluído.

Outra implicação prática diz respeito a potenciais problemas em análises de atos de concentração por órgãos de defesa da concorrência quando não se considera a questão da Separabilidade fraca. Isso ocorre porque, de acordo com o Departamento de Estudos Econômicos - DEE (2010) do Conselho Administrativo de Defesa Econômica, a determinação da demanda, e sua estatística síntese, a elasticidade, serve de insumo para várias etapas na análise de defesa da concorrência, como por exemplo, a determinação do mercado relevante, o grau de rivalidade e a simulação dos impactos das fusões. No primeiro caso, os pareceres mais recentes relacionados à delimitação de mercado relevante geralmente baseiam-se em técnicas que envolvem a estimação de elasticidades, tal como o Teste do Monopolista Hipotético (TMH). Assim, a hipótese de Separabilidade, ao restringir o grau de substituição entre os bens de grupos diferentes, é fundamental para determinar o mercado relevante e assim julgar atos de concentração. Em relação ao poder de mercado e a análise de fusões, Huse \& Salvo (2006) mostram como modelos de demanda bem definidos são ferramenta fundamental na obtenção de equilíbrios pós-fusão, efeitos de integração vertical, reações a mudanças de preços etc. Assim, novamente aqui a hipótese de Separabilidade fraca tem papel crucial nessa definição.

Apesar da importância do conceito de separabilidade fraca, os trabalhos sobre demanda no Brasil ${ }^{3}$ não testam essa hipótese, e consideram a priori que os bens analisados são separáveis dos demais. Por outro lado, internacionalmente, diversos trabalhos foram realizados com o objetivo de testar a separa-

\footnotetext{
${ }^{2}$ Em consequência, os procedimentos habituais para determinação de intervalos de confiança e testes de hipóteses provavelmente conduzirão a conclusões equivocadas quanto à significância estatística dos parâmetros estimados. Além disso, outra consequência é que as previsões alicerçadas no modelo incorreto e os intervalos de confiança estimados não serão confiáveis (Greene 2008).

${ }^{3}$ Ver, por exemplo, Coelho et al. (2010), Resende Filho et al. (2012), Rodrigues et al. (2012).
} 
bilidade fraca de bens em diversas especificações de demanda ${ }^{4}$. Os resultados desses trabalhos indicam que testar a hipótese de separabilidade fraca é fundamental para a correta especificação de um sistema de demanda. Os efeitos de se assumir uma especificação a priori podem ser a obtenção de estimativas das elasticidades enganosas e que levam a conclusões equivocadas.

Dessa forma, como ressaltado, não é de nosso conhecimento que algum trabalho nacional tenha testado a hipótese da separabilidade fraca em sistemas de demanda, evidenciando a importância do presente trabalho. Portanto, o objetivo do trabalho é testar esaa hipótese em um sistema de demanda de carnes no Brasil, utilizando os microdados da POF 2008-09. O intuito é verificar se o grupo Carnes é fracamente separável do grupo de Outros alimentos, sendo possível utilizar apenas o preço e o dispêndio com carnes para a estimação da demanda no grupo, como é usual. Além disso, pretende-se verificar se os segmentos oriundos do grupo Carnes são fracamente separáveis por tipo de animal, ou seja, se é melhor realizar uma análise desagregada da demanda por carnes em seus respectivos subgrupos para um melhor entendimento das mudanças de preferências. Por fim, por meio da análise do conceito de separabilidade fraca, será possível verificar como seria o formato da árvore de utilidade para a demanda pelo bem no Brasil.

O presente trabalho está dividido em quatro seções, incluindo esta introdução. Na segunda seção, apresenta-se o referencial teórico utilizado neste estudo; na terceira, o procedimento adotado para testar a separabilidade fraca em diversas árvores de utilidade em um sistema de demanda de carnes no Brasil. Na quarta seção, são apresentados os resultados e discussão sobre os testes de separabilidade fraca para a demanda por carnes e as consequências da não utilização do conceito em estimações de demanda. A quinta seção apresenta as considerações finais.

\section{Referencial teórico}

\subsection{Referencial teórico}

Sendo praticamente impossível incluir todos os bens no processo de otimização da escolha do consumidor, uma alternativa é assumir que o mesmo pode tomar certas decisões de consumo separadamente. De acordo com Deaton e Muellbauer (1980a), se existe o vetor de bens $q$ na forma $\left(q_{g}, q_{\bar{g}}\right)$, em que $q_{g}$ é o vetor bens no grupo $G$ e $q_{\bar{g}}$ é o vetor dos bens fora do grupo $G$, então para qualquer vetor arbitrário $q_{\bar{g}}$, diz-se que a preferência dos consumidores em relação à q definirá uma ordenação condicional dos bens no grupo $q_{g}$, dependendo, portanto, dos bens fora do grupo $G, q_{\bar{g}}$. Assim, quando esta ordenação condicional dos bens no grupo for independente dos níveis de consumo fora do grupo, é possível dizer que o grupo é separável. Nesse caso, pode-se inferir que, sendo $U\left(q_{1}, q_{2}, \ldots, q_{n}\right)$ uma função de utilidade e considerando três grupos de bens $(A, B, C)$, a separabilidade fraca pode ser representada por ( $A n$ Almost Ideal Demand System 1980):

\footnotetext{
${ }^{4}$ Dentre os trabalhos internacionais que utilizaram testes não paramétricos para analisar a separabilidade fraca pode-se citar: Afriat (1967), ?), Swofford \& Whitney (1987). Dentre os que utilizaram testes paramétricos, destacam-se ainda: Byron (1970), Jorgenson \& Lau (1975), Pudney (1981), Eales \& Unnevehr (1988), Moschini et al. (1994), Eales \& Wessels (1999), Njonou et al. (2002), Lambert et al. (2006).
} 


$$
\text { ex. } U(q)=U\left(q_{1}, \ldots, q_{k}\right)=U\left[U_{A}\left(q^{A}\right), U_{B}\left(q^{B}\right), U_{C}\left(q^{C}\right)\right],
$$

A consequência direta da hipótese apresentada acima é que a demanda por um bem pode ser estimada usando apenas variáveis daquele grupo. Considerando o bem $j$ do grupo $A$ :

$$
q_{A j}=g_{A j}\left(p_{A}, m_{A}\right)
$$

Em que $q_{A j}$ é a demanda marshalliana do bem $j$ pertencente ao grupo $A$; $m_{A}=\sum_{j=1}^{n} p_{A i} q_{A i}$ é o total de gastos no grupo $A$; e $p_{A}$ é o vetor de preços dos bens que compõem o grupo $A$.

Portanto, de maneira simplificada, a condição necessária e suficiente para uma função ser fracamente separável é que a taxa marginal de substituição entre duas variáveis pertencentes ao mesmo grupo seja independente do valor de qualquer outra variável pertencente a outro grupo (Gorman 1981). Assim, a separabilidade fraca impõe uma série de restrições nos graus de substitubilidade entre os bens em diferentes grupos. Supondo que $i \in A$ e $j \in B$, com $A \neq B$, diferenciando 2 com respeito à $p_{j}$ e mantendo $u$ constante (ou seja, usando a demanda hicksiana ou compensada $h_{i}(u, p)$, o único efeito deve ser por meio de $m_{A}$. Assim (Deaton \& Muellbauer 1980):

$$
\frac{\partial h_{i}(u, p)}{\partial p_{j}}=S_{i j}=\frac{\partial q_{i}}{\partial m_{A}} \cdot \frac{\partial m_{A}}{\partial p_{j}}, \quad \text { com } u \text { constante }
$$

Da mesma forma:

$$
\frac{\partial h_{i}(u, p)}{\partial p_{j}}=S_{j i}=\frac{\partial q_{j}}{\partial m_{B}} \cdot \frac{\partial m_{B}}{\partial p_{i}}, \quad \text { com } u \text { constante }
$$

Como $S_{i j}=S_{j i}$ por simetria, igualando as expressões acima e dividindo, tem-se:

$$
\frac{\frac{\partial m_{A}}{\partial p_{j}}}{\frac{\partial q_{j}}{\partial m_{B}}}=\frac{\frac{\partial m_{B}}{\partial p_{i}}}{\frac{\partial q_{i}}{\partial m_{A}}}, \quad \text { com } u \text { constante }
$$

O lado esquerdo da equação 5 não envolve o bem $i$, e nem o lado direito envolve o bem $j$. Dessa forma, toda a expressão é independente de ambos (só depende dos grupos $A$ e $B^{5}$ ) e pode ser representada por $\lambda_{A B}$. Assim:

$$
\frac{\partial m_{A}}{\partial p_{j}}=\lambda_{A B} \frac{\partial q_{j}}{\partial m_{B}}, \quad \text { com } u \text { constante }
$$

Substituindo em 3:

$$
S_{i j}=\mu_{A B} \frac{\partial q_{i}}{\partial m_{B}} \cdot \frac{\partial q_{j}}{\partial m},
$$

\footnotetext{
${ }^{5}$ Fazendo, por exemplo, $S_{i k}=S_{k i}$, com $k \neq j$, mas $k$ pertencendo ao mesmo grupo $B$ de $j$, tem-se: $\frac{\partial m_{A} / \partial p_{k}}{\partial q_{k} / \partial m_{B}}=\frac{\partial m_{B} / \partial p_{i}}{\partial q_{i} / \partial m_{A}}$, com $u$ constante. Da expressão acima e da equação 5 , teríamos $\frac{\partial m_{a} / \partial p_{k}}{\partial q_{k} / \partial m_{b}}=\frac{\partial m_{A} / \partial p_{j}}{\partial q_{j} / \partial m_{B}}$, com $u$ constante. Como $j$ e $k$ são bens quaisquer do grupo $B$, percebe-se que a expressão não depende do bem escolhido, e sim do grupo analisado. O mesmo poderia ter sido feito para $i$, com, por exemplo, $S_{n j}=S_{j n}$, com $n$ e $i$ do mesmo grupo.
} 
Sendo:

$$
\mu_{A B} \cdot \frac{\partial m_{A}}{\partial m} \cdot \frac{\partial m_{B}}{\partial}=\lambda_{A B}
$$

Portanto, a condição necessária e suficiente para separabilidade fraca é que a substituição entre bens de grupos distintos devido a uma mudança de preços seja proporcional às derivadas do dispêndio. Dessa forma, o efeito compensado de uma mudança de preços é simplesmente realocar o dispêndio entre grupos.

É importante dizer que a expressão acima mostra que as quantidades demandadas em um grupo não são independentes dos preços dos bens nos outros grupos ou do gasto total. Dessa forma, quando os preços de bens de outros grupos se modificam, o montante do gasto total alocado para cada grupo também irá se modificar. Assim, o consumidor irá realocar os gastos de cada bem em resposta a mudanças de preços relativos, pois o montante total é fixo. Como $\mu_{A B}$ é desconhecido, é possível eliminar essa constante dividindo $S_{i k}$ por $S_{j k}$, em que $k$ é outro bem pertencente ao grupo $A$ :

$$
\frac{S_{i k}}{S_{j k}}=\frac{\frac{\partial q_{i}}{\partial m}}{\frac{\partial q_{j}}{\partial m}}
$$

\section{Metodologia}

\subsection{Forma Funcional}

As condições de separabilidade fraca resumidas pela equação 7 podem ser mantidas ou testadas por meio de uma especificação paramétrica de um sistema de demanda. Neste estudo, utiliza-se a especificação denominada Quadratic Almost Ideal Demand System - QUAIDS de Banks et al. (1997), da mesma forma que em Coelho et al. (2010). Essa forma funcional é flexível, compatível com os postulados da Teoria do Consumidor (Banks et al. 1997), e permite impor facilmente as propriedades da função de demanda (homogeneidade e simetria), que dependem apenas dos parâmetros estimados no modelo. Além disso, incorpora os efeitos não lineares do dispêndio, cuja ausência pode gerar estimativas enviesadas, devido à especificação inadequada das equações de demanda. O QUAIDS é expresso da seguinte forma:

$$
w_{i}=\alpha_{i}+\sum_{j} \gamma_{i j} \ln p_{j}+\beta_{i} \ln \frac{m}{a(p)}+\frac{\lambda_{i}}{b(p)}\left\{\ln \left(\frac{m}{a(p)}\right)\right\}^{2}
$$

Em que $w_{i}=\frac{p_{i} q_{i}}{\sum_{i=1}^{n} p_{i} q_{i}}$ é a parcela de gastos com o $i$-ésimo bem; $\ln \alpha(p)=$ $\alpha_{0}+\sum_{i} \alpha_{i} \ln v\left(p_{i}\right)+1 / 2 \sum_{i} \sum_{j} \gamma_{i j} \ln \left(p_{i}\right) \ln \left(p_{j}\right) ; b(p)=\prod_{i} p_{i}^{\beta_{k}} ; \lambda(p)=\sum_{i=1}^{n} \lambda_{i} \ln p_{i}$, sendo $\sum_{i} \lambda_{i}=1 ; m$ é o dispêndio total com $n$ bens; $p_{j}$ é o preço do $j$-ésimo bem; e $\alpha_{i}, \gamma_{i j}, \beta_{i}$ e $\lambda_{i}$ são os parâmetros a serem estimados, sendo o último, o parâmetro requerido para o termo quadrático do dispêndio.

\subsection{Procedimentos econométricos}

Apesar do uso de microdados, como os disponibilizados pelas pesquisas de orçamentos familiares (POFs), na estimação de equações de demanda de ali- 
mentos permitir uma melhor especificação das mesmas, com a inclusão de variáveis que captam a heterogeneidade entre os consumidores, seu uso não deixa de apresentar problemas que devem ser resolvidos pelo pesquisador. $\mathrm{O}$ maior desses problemas é o fato de o nível de desagregação geralmente resultar num grande número de famílias não consumindo um produto em específico. Esse problema é conhecido como Problema do Consumo Zero (PCZ), e impõe uma série de restrições sobre quais métodos econométricos podem ser usados para estimar de forma correta as equações de demanda.

Desse modo, a não consideração do Problema do Consumo Zero gera estimativas enviesadas e inconsistentes dos sistemas de demanda. Portanto, para lidar com esse problema, utiliza-se o procedimento de ?, os quais propõem um método de estimação em dois estágios, que permite englobar todas as observações. No primeiro estágio (Decisão de compra), estima-se um modelo probit para determinar a probabilidade de determinado domicílio consumir o item, em função das características sócio-demográficas ${ }^{6}$. Já o segundo estágio considera a estimação do sistema de demanda. O procedimento é descrito da seguinte forma:

$$
\begin{gathered}
1{ }^{\circ} \text { estágio } \\
d_{i k}^{*}=z_{i k}^{\prime} \alpha_{i}+\vartheta_{i k}, \\
d_{i k}= \begin{cases}1, & \operatorname{sed}_{i k}^{*}>0 \\
0, & \operatorname{sed}_{i k}^{*} \leq 0\end{cases} \\
2^{\circ} \text { estágio } \\
w_{i k}^{*}=f\left(x_{i k}, \beta_{i}\right)+\epsilon_{i k}, \\
w_{i k}^{*}=d_{i k}^{*} w_{i k}^{*},(i=1, \ldots, m ; k=1, \ldots, K)
\end{gathered}
$$

em que $d_{i k}^{*}$ é a variável latente representando a diferença em utilidade entre comprar ou não o i-ésimo bem; $d_{i k}$ e a variável binária observada para representar a escolha do k-ésimo domicílio em consumir i-ésimo bem $\left(d_{i k}=1\right)$ ou não $\left(d_{i k}=0\right) ; w_{i k}^{*}$ é a variável latente representando a parcela de gastos com o $i$-ésimo bem; $w_{i k}$ é a variável dependente observada representando a parcela de gastos com o $i$-ésimo bem; $f\left(x_{i k}, \beta_{i}\right)$ é a função de demanda (QUAIDS); $z_{i k}$ e $x_{i k}$ são vetores de variáveis exógenas; $\beta_{i}$ e $\alpha_{i}$ são vetores de parâmetros; e $\epsilon_{i k}$ e $\vartheta_{i k}$ são os erros aleatórios.

No primeiro estágio, obtêm-se as estimativas de $\alpha_{i}$ por meio do modelo probit. Calcula-se a função de densidade de probabilidade $\phi\left(z_{i k}^{\prime} \hat{\alpha_{i}}\right)$ e a função de acumulada $\Phi\left(z_{i k}^{\prime} \hat{\alpha}_{i}\right)$. Em seguida, estima-se $w_{i k}$ por SUR (regressões aparentemente não correlacionadas) da seguinte forma:

$$
w_{i k}=\Phi\left(z_{i k}^{\prime} \hat{\alpha}_{i}\right) f\left(x_{i k}, \beta_{i}\right)+\varphi_{i} \phi\left(z_{i k}^{\prime} \hat{\alpha}_{i}\right)+\epsilon_{i k}
$$

\section{Correção da endogeneidade}

\section{Endogeneidade dos preços (valores unitários)}

Na Pesquisa de Orçamentos Familiares (POF), o preço pago pelo bem $p_{i}$ não é disponibilizado, e sim a despesa total com a compra do bem e a quanti-

\footnotetext{
${ }^{6}$ Ver Quadro 1 para as variáveis utilizadas
} 
dade adquirida com o mesmo. Assim, o preço com o i-ésimo bem pode ser representado pelo valor unitário de cada bem $\left(U V_{i}\right)$, calculado pela divisão do dispêndio com o $i$-ésimo bem pelo k-ésimo domicílio $\left(m_{i k}\right)$ pela quantidade adquirida com o $i$-ésimo bem pelo k-ésimo domicílio $\left(m_{i k}\right)$, expresso da seguinte forma (?):

$$
U V_{i k}=\frac{m_{i k}}{q_{i k}},
$$

Entretanto, Cox \& Wohlgenant (1986) e Deaton (1988) alertaram que a utilização de valores unitários pode comprometer a estimação da equação de demanda, pois é comum que eles não sejam exógenos, incorporando atributos como qualidade do bem. De forma geral, como consumidores com maior renda tendem a comprar bens de maior qualidade, os valores unitários serão positivamente correlacionados com o dispêndio total. Assim, como os valores unitários são variáveis de escolha, há um risco de viés de simultaneidade em qualquer tentativa de explicar padrões de demanda utilizando valores unitários.

Para solucionar esse problema, aplica-se o método de Cox \& Wohlgenant (1986), que consiste em estimar os preços corrigidos pelos "efeitos qualidade", regredindo a diferença entre $U V_{i k}$ e seus valores médios por estado $(\overline{U V})$, pelas características domiciliares. Assim:

$$
U V_{i k}-\overline{U V}=\sum_{t} \eta_{i k} z_{i k}+u_{i}
$$

em que $z_{i k}$ são as características do k-ésimo domicílio (Tabela 1) utilizado como proxy das preferências dos domicílios por qualidade. Assume-se que os desvios em relação aos valores unitários médios refletem "efeitos qualidade" induzidos por características domiciliares, como também fatores não sistemáticos ligados à oferta. Os preços ajustados $\left(p_{i k}\right)$ são obtidos da seguinte forma:

$$
p_{i k}=U V_{i k}-\sum_{t} \hat{\eta}_{i k} z_{i k}
$$

\begin{tabular}{|c|c|}
\hline Variáveis & Descrição \\
\hline Urbano & Localizado na zona urbana $=1 ;$ caso contrário $=0$ \\
\hline Norte & Localizado na região Norte $=1 ;$ caso contrário $=0$ \\
\hline Nordeste & Localizado na região Nordeste $=1$; caso contrário $=0$ \\
\hline Sul & Localizado na região $\mathrm{Sul}=1$; caso contrário $=0$ \\
\hline Centro Oeste & $\begin{array}{l}\text { Localizado na região Centro Oeste }=1 \text {; caso contrário }=0 \\
\text { Composição Domiciliar }\end{array}$ \\
\hline Renda* & Renda domiciliar per capita \\
\hline Sexo & Chefe de família do sexo feminino $=1 ;$ caso contrário $=0$ \\
\hline Escolaridade & Anos de estudo do chefe de família \\
\hline Criança & Possui criança $=1 ;$ caso contrário $=0$ \\
\hline Adolescente & Possui adolescentes $=1$; caso contrário $=0$ \\
\hline Idosos & Presença de idosos $=1$; caso contrário $=0$ \\
\hline
\end{tabular}

Tabela 1: Variáveis presentes nos vetores $z_{i k}$ e $D_{k}$

${ }^{*}$ Presente apenas no vetor $z_{i k}$. 
Vale ressaltar que, para os domicílios que não consumiram o $i$-ésimo bem, ou seja, $q_{i}=0$, são imputados os preços médios estaduais $\overline{p_{i}}$ calculados para cada estado do Brasil.

\section{Endogeneidade do dispêndio}

Se confirmado que o consumo de carnes é fracamente separável do dispêndio total com alimentos, assume-se que a quantidade demandada do $i$-ésimo bem considerado $\left(q_{i}\right)$ é uma função do dispêndio com carnes $\left(m_{r}\right)$. Entretanto, é possível que exista um viés de simultaneidade, devido à determinação conjunta da quantidade demandada de carnes $\left(q_{r}\right)$ e seu dispêndio $\left(m_{r}\right)$. Dessa forma, não se pode considerar o dispêndio com carnes estritamente exógeno (Lafrance 1991).

Assim, para corrigir essa possível endogeneidade, utiliza-se o procedimento de regressão aumentada de Blundell \& Robin (1999): estima-se uma regressão do total de despesas com carnes no domicílio $\mathrm{k}\left(m_{r k}\right)$ em relação ao dispêndio total com alimentos desse domicílio $\left(m_{k}\right)$ e o vetor de características domiciliares $z_{k}$, incluídas como variáveis de controle:

$$
\ln m_{r k}=\alpha_{0}+\sum_{k} \alpha_{k} z_{k}+b \ln m_{k}+v_{k}
$$

Em seguida, utiliza-se o resíduo $\left(v_{k}\right)$ estimado pela equação (18) como variável explicativa na equação de demanda, juntamente com o dispêndio com carnes $\left(m_{r k}\right)$.

\subsection{Modelo econométrico}

O sistema de demanda estimado pelo segundo estágio do procedimento de Shonkwiller e Yen, além de considerar os preços e o dispêndio, também considera outras variáveis $D_{i k}$ (Tabela 1) que também influenciam a demanda domiciliar por carnes, ou seja, incorporam-se no sistema essas variáveis por meio da translação demográfica linear (?). Dessa forma:

$$
\begin{gathered}
w_{i k}=\left[\sum_{k} \theta_{i k} D_{i k}+\alpha_{i}+\sum_{j} \gamma_{i j} \log p_{j}+\beta_{i} \log \left(\frac{m_{r k}}{a(p)}\right)+\frac{\lambda_{i}}{b(p)}\right. \\
\left.\left\{\log \frac{m_{r k}}{a(p)}\right\}^{2}+\pi_{i} \hat{v}_{k}\right] \phi\left(z_{i k}^{\prime} \hat{\alpha}_{i}\right)+\delta_{i} \phi\left(z_{i k}^{\prime} \hat{\alpha}_{i}\right)+\epsilon_{i k},
\end{gathered}
$$

em que $\phi\left(z_{i}^{\prime} k \hat{\alpha}_{i}\right)$ é a função de densidade de probabilidade calculada no primeiro estágio do procedimento de Shonkwiller e Yen; $D_{i k}$ é um vetor de variáveis (Tabela 1) que caracterizam o k-ésimo domicílio; $\theta_{i k}$ são os parâmetros estimados para cada variável; $b(p)=\prod_{n} p_{k}^{\beta_{\alpha}}$ é um agregador de preços CobbDouglas; $\Phi\left(z_{i k}^{\prime} \hat{\alpha}_{i}\right)$ é a função de distribuição acumulada também calculada no primeiro estágio do procedimento de Shonkwiller e Yen; $\pi_{i}$ é o parâmetro do resíduo $\left(\hat{v}_{k}\right)$ estimado em (18) e $\epsilon_{i k}$ é o erro aleatório com média zero. Ressaltase que, ainda que o procedimento de Shonkwiller e Yen seja o mais adequado para a estimação de sistemas de demanda, os erros-padrão estimados pela equação do segundo estágio podem estar viesados, devido à presença de um regressor gerado no primeiro estágio de estimação. Desse modo, foi realizado 
um procedimento de bootstrap para a obtenção de erros-padrão robustos para os parâmetros do segundo estágio e consequentemente para as elasticidades obtidas.

O vetor $D_{k}$ é formado por variáveis que permitem captar as diferenças no padrão de consumo entre os domicílios, em relação à localização e composição. No primeiro grupo de variáveis, encontram-se às que definem a localização domiciliar, permitindo verificar as diferenças de consumo entre as regiões geográficas e as zonas de residência. Assim, utiliza-se uma variável que identifica a diferença de consumo entre as áreas urbanas e rurais. Para as dummies que representam as regiões geográficas, a região Sudeste é considerada como base de comparação, pois é a região que tem maior participação dos grupos alimentares. As variáveis de composição domiciliar podem captar como a estrutura familiar e as características do responsável pelo domicílio contribuem na aquisição das Carnes. Considerou-se como variáveis categóricas: uma variável que identifica se o responsável pelo domicílio é do sexo feminino, se existem crianças ou adolescentes, e se existem idosos ${ }^{7}$. Incluiu-se também uma variável que identifica a escolaridade do responsável (IBGE 2010). A análise descritiva de todas as variáveis utilizadas é apresentada na Tabela A.1, no Apêndice.

Estimam-se as equações de demanda por um sistema não linear de regressão aparentemente não relacionada (SUR), de acordo com o comando NLSUR do STATA. O método utilizado foi o IFGNLS (iterated feasible generalized nonlinear least squares), semelhante às estimações de Máxima Verossimilhança. Ressalta-se que os sistemas de demanda testados para a separabilidade fraca no presente trabalho foram estimados sem a imposição das restrições de homogeneidade e simetria, para que a imposição destas restrições não influencie nos resultados dos testes de separabilidade. A restrição de aditividade foi atendida automaticamente com a retirada de uma equação (Outros alimentos) na estimação de cada sistema de demanda e a posterior recuperação dos parâmetros da equação omitida.

\subsection{Teste de Separabilidade Fraca}

Testar a separabilidade fraca implica testar a validade da equação (9) para o sistema de demanda. Entretanto, tal equação ainda pode ser expressa de acordo com as elasticidades-dispêndio dos respectivos bens. Seja $\varphi_{i j}$ a elasticidade substituição de Allen-Uzawa ${ }^{8}$ entre os bens $i$ e $j$, tal que $\varphi_{i j}=e_{i j}^{c} / w_{j}$, em que $e_{i j}^{c}=e_{i j}^{u}+e_{i} w_{j}$ é a elasticidade preço-cruzado compensada e $w_{j}=p_{j} q_{j} / m$ é a parcela de gastos pelo bem $j$. Então, definindo a elasticidade-dispêndio como $e_{i}=\left(\partial q_{i} / \partial m\right)\left(m / q_{i}\right)$, a equação (9) pode ser expressa como:

$$
\frac{\varphi_{i k}}{\varphi_{j n}}=\frac{e_{i} e_{k}}{e_{j} e_{n}}
$$

\footnotetext{
${ }^{7}$ As definições utilizadas foram as seguintes: criança: indivíduos com idade menor ou igual a 12 anos; adolescente: indivíduos com idade entre 12 e 18 anos; e idoso: indivíduos com idade acima de 60 anos.

${ }^{8}$ Esta, em sua mais simples expressão conceitual, mede a magnitude do efeito de uma mudança na razão de preços $\left(P_{i} / P_{j}\right)$ sobre a relação $j / i$, em termos de quantidade. Reflete a substituição entre os bens, quando o sinal é positivo, e complementariedade, quando o sinal é negativo; além de fornecer uma descrição da estrutura de demanda, bem como a interdependência no mercado dos respectivos bens (Moschini et al. 1994).
} 
para todo $(i, j) \in A$ e $(n, k) \in B$, para todo $A \neq B$.

Portanto, as condições de separabilidade fraca resumidos pelas restrições de elasticidade originadas da equação 20 podem ser testadas sobre uma especificação paramétrica de um sistema de demanda. No caso do presente trabalho, essa especificação é o modelo QUAIDS e, assim, usando os termos do modelo já definidos anteriormente, a elasticidade de substituição $\left(\varphi_{i} k\right)$ e a elasticidade-renda $\left(e_{i}\right)$ são representadas por:

$$
\begin{gathered}
\varphi_{i k}=\frac{e_{i} w_{i} w_{k}+\gamma_{i k}-\mu_{i}\left(\alpha_{k}+\sum_{j} \gamma_{k j} \ln p_{j}\right)-\frac{\lambda_{i} \beta_{k}}{b(p)}\left\{\left(\frac{m}{a(p)}\right)\right\}^{2}}{w_{i} w_{k}} \\
e_{i}=\frac{\mu_{i}}{w_{1}}+1,
\end{gathered}
$$

com $\mu_{i} \equiv \frac{\partial w_{i}}{\partial \ln m}=\beta_{i}+\frac{2 \lambda_{i}}{b(p)}\left\{\ln \left(\frac{m}{a(p)}\right)\right\}$. Assim, a restrição de separabilidade fraca em (20) pode ser escrita como:

$$
\frac{\gamma_{i k} w_{i} w_{k}+w_{k} \mu_{i}-\mu_{i}\left(\alpha_{k}+\sum_{j} \gamma_{k j} \ln p_{j}\right)-\frac{\lambda_{i} \beta_{k}}{b(p)}\left\{\left(\frac{m}{a(p)}\right)\right\}^{2}}{\gamma_{j k} w_{j} w_{k}+w_{k} \mu_{j}-\mu_{j}\left(\alpha_{k}+\sum_{j} \gamma_{k l} \ln p_{l}\right)-\frac{\lambda_{j} \beta_{k}}{b(p)}\left\{\left(\frac{m}{a(p)}\right)\right\}^{2}}=\frac{\left(w_{i}+\mu_{i}\right)\left(w_{k}+\mu_{k}\right)}{\left(w_{j}+\mu_{j}\right)\left(w_{m}+\mu_{m}\right)}
$$

em que $(i, j) \in A$ e $(k, m) \in B$, para todo $A \neq B$.

Testam-se as restrições de separabilidade fraca em apenas um ponto, como sugerido por Jorgenson \& Lau (1975) e por Denny \& Fuss (1977). Um ponto de interesse é a média das variáveis explicativas: nesse caso, Moschini et al. (1994) afirmam que é interessante normalizar todos os preços e dispêndio de forma que eles sejam iguais a um na média. Assim, fazendo essa normalização, para o modelo QUAIDS, $\log \left[m / \alpha_{0}=-\alpha_{0}\right.$ e $b(p)=1$, com $p_{i}=1$, no ponto médio. Pela equação 10, têm-se:

$$
\begin{gathered}
w_{i}=a_{i}-\beta_{i} \alpha_{0}+\lambda_{i}\left(\alpha_{0}\right)^{2}, \\
\mu_{i}=\beta_{i}-2 \lambda \alpha_{0},
\end{gathered}
$$

Substituindo 24 e 25 em 23, define-se o conjunto de restrições de separabilidade fraca não-lineares que envolvem apenas os parâmetros do modelo QUAIDS, sendo estas restrições cabíveis de serem mantidas ou testadas. No entanto, devido ao fato de o parâmetro $\alpha_{0}$ ser virtualmente impossível de se estimar em aplicações empíricas, Deaton \& Muellbauer (1980) sugerem fixar $\alpha_{0}$ antes de estimar todos os parâmetros. O motivo para o problema de estimação é que a função de verossimilhança típica é linear em $\alpha_{0}$, sugerindo que a escolha deste não afeta as propriedades do modelo QUAIDS ${ }^{9}$. Assim, um critério alternativo e particularmente usual para a solução desse problema é fixar $\alpha_{0}=0$. Nesse caso, a restrição de separabilidade fraca local [no ponto médio $(p, y)=(1,1)]$ é reduzida para:

$$
\frac{\gamma_{i k}+\alpha_{i} \alpha_{k}}{\gamma_{j m}+\alpha_{j} \alpha_{m}}=\frac{\left(\alpha_{i}+\beta_{i}\right)\left(\alpha_{k}+\beta_{k}\right)}{\left(\alpha_{j}+\beta_{j}\right)\left(\alpha_{m}+\beta_{m}\right)}
$$

\footnotetext{
${ }^{9}$ De acordo com Moschini et al. (1994), espera-se que as elasticidades calculadas não sejam influenciadas pela escolha de $\alpha_{0}$.
} 
Para implementar as restrições de separabilidade fraca oriundas da equação 26, é importante saber o número de restrições que estão implícitas de acordo com a estrutura separável assumida. Se n é o número total de bens, existe um total de $1 / 2 n(n-1)$ termos de substituição-cruzados $\left.\left(\partial h_{i}\right) / \partial p_{j}, i \neq j\right)$. Se $n_{s}$ é o número de bens pertencente ao grupo $s(s=1,2, \ldots, S)$, então existem $1 / 2\left[\sum_{s} n_{s}\left(n_{s}-1\right)\right]$ termos de substituição-cruzados dentro do grupo. Portanto, a diferença entre as duas quantidades de termos de substituição-cruzados gera o número de termos de substituição que dizem respeito aos bens pertencentes a diferentes grupos, $n_{0}$. Além disso, haverá $n_{\mu}=\left(\begin{array}{l}S \\ 2\end{array}\right)$ coeficientes de proporcionalidade $\mu$ que identificam completamente os $n_{0}$ termos de substituiçãocruzado devido aos efeitos renda. Assim, $n_{\mu}=1 /(2) S(S-1)$, e o número de restrições não redundantes $\left(n_{r}=\left(n_{0}-n_{\mu}\right)\right)$ implícitas pela equação 26 é dado por (Moschini et al. 1994):

$$
n_{r}=1 / 2\left[n(n-1)-\sum_{s=1}^{s} n_{s}\left(n_{s}-1\right)-S(S-1)\right],
$$

Para testar a separabilidade fraca neste estudo, foram estabelecidas a priori determinadas árvores de utilidade, e os parâmetros de restrição aplicados em cada árvore foram testados pelo Teste de Razão de Verossimilhança (Likelihood Ratio Test) - LR, definido como:

$$
L R=2[L(\hat{\beta})-L(\tilde{\beta})]
$$

em que $L($.$) indica o valor maximizado da função logarítmica da razão de pro-$ babilidade, $\beta$ é o estimador irrestrito do vetor de parâmetros, e $\beta$ é o vetor do parâmetro avaliado sob as restrições de separabilidade fraca.

Entretanto, de acordo com Meisner (1979), testes de separabilidade fraca em grandes sistemas de demanda possuem viés para a rejeição. Isso ocorre devido à utilização de uma estimativa da matriz de covariância ao invés da matriz verdadeira. Desse modo, sugere-se uma correção para tamanho (sizecorrection) para o teste $L R$. O método proposto por Italianer (1985), segundo Moschini et al. (1994), é a melhor solução encontrada para a correção do procedimento e baseia-se na seguinte equação:

$$
L R_{0}=L R\left[\frac{M T-\frac{1}{2}\left(N_{U}+N_{R}\right)-\frac{1}{2} M(M-1)}{M T}\right]
$$

em que $M$ é o número de equações; $T$ é o número de observações (por isso, existem, efetivamente, $M T$ observações na amostra e $1 / 2 M(M+1)$ termos na matriz de covariância); $N_{U}$ é o número de parâmetros do modelo irrestrito; e $N_{R}$ é o número de parâmetros do modelo restrito (separável).

\section{Árvores de utilidade testadas}

Os sistemas de demanda estimados no trabalho contêm sete bens agregados 10 , sendo eles: $q_{1}=$ Frango inteiro; $q_{2}=$ Partes processadas do frango; $q_{3}=$ Outras carnes suínas; $q_{4}=$ Carnes suínas com e sem osso; $q_{5}=$ Cortes bovinos de segunda e outros; $q_{6}=$ Cortes nobres bovinos e $q_{7}=$ Outros alimentos. $\mathrm{O}$ conjunto de árvores de utilidade utilizadas no trabalho foi especificada com

\footnotetext{
${ }^{10}$ Ver Quadros 2 e 3 para uma descrição detalhada desses bens
} 
base em características do setor de carnes, na classificação utilizada pelo IBGE (IBGE 2010), além do estudo de Eales \& Unnevehr (1988) (Tabela 2).

Pode-se exemplificar graficamente as árvores de utilidade testadas. Por exemplo, a árvore 1 objetiva verificar a separabilidade fraca apenas entre as Carnes e os Outros Alimentos (1). Já a segunda árvore propõe a separabilidade fraca entre os Outros alimentos e as Carnes, sendo estas separáveis em seus respectivos subgrupos: carnes de frango (Frango inteiro e Partes processadas do frango), carne suína (Outras carnes suínas e Carne suína com e sem osso) e carne bovina (Cortes bovinas de segunda e outras e Cortes nobres bovinos) (2). $\mathrm{Na}$ terceira árvore de utilidade, os Outros alimentos são separáveis das Carnes, porém estas são separáveis em Carnes de primeira (Partes processadas do frango e Cortes nobres bovinos), Carnes de segunda (Frango inteiro e Cortes bovinos de segundo) e Carnes suínas. A quarta árvore de utilidade aborda a separabilidade fraca entre os Outros alimentos e as Carnes, entretanto estas são subdivididas em Carnes de primeira e Carnes de segunda incluindo as Carnes suínas. A quinta árvore de utilidade também separa os outros alimentos das Carnes, porém estas se subdividem em Carnes de segunda e as Demais carnes. Na sexta árvore de utilidade, novamente os Outros alimentos estão separados das Carnes, no entanto, estas são divididas em Carnes de primeira e Demais carnes. Na sétima árvore, testa-se a separabilidade fraca entre Carnes de segunda e os Demais alimentos. Por fim, a oitava árvore de utilidade é semelhante à sétima, porém a separabilidade é testada entre as Carnes de primeira e os Demais alimentos.

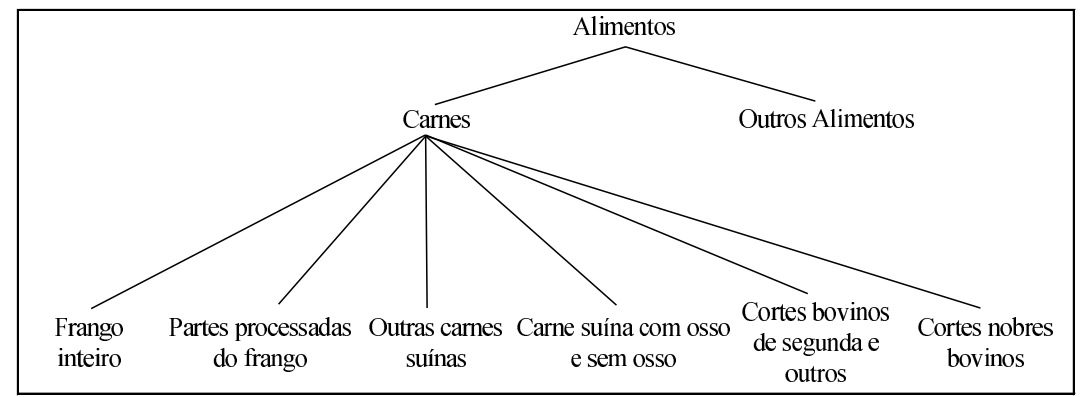

Fonte: Elaboração própria

Figura 1: Árvore de utilidade 1

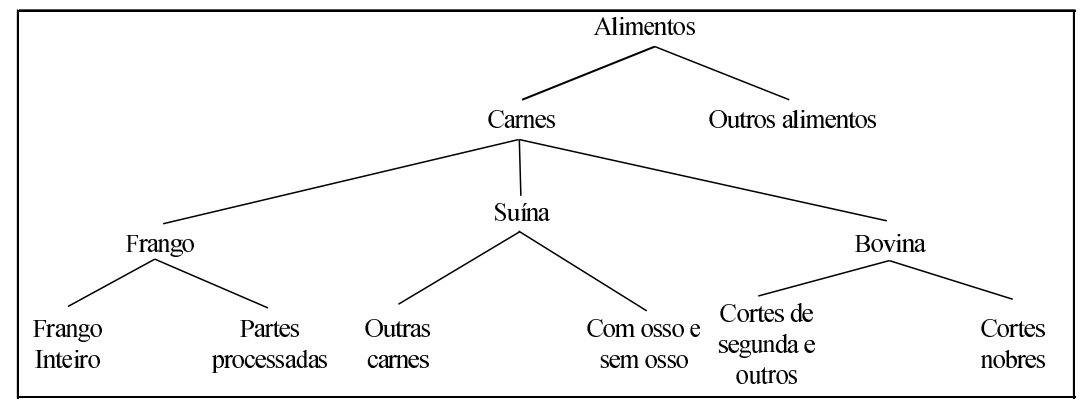

Fonte: Elaboração própria

Figura 2: Árvore de utilidade 2 


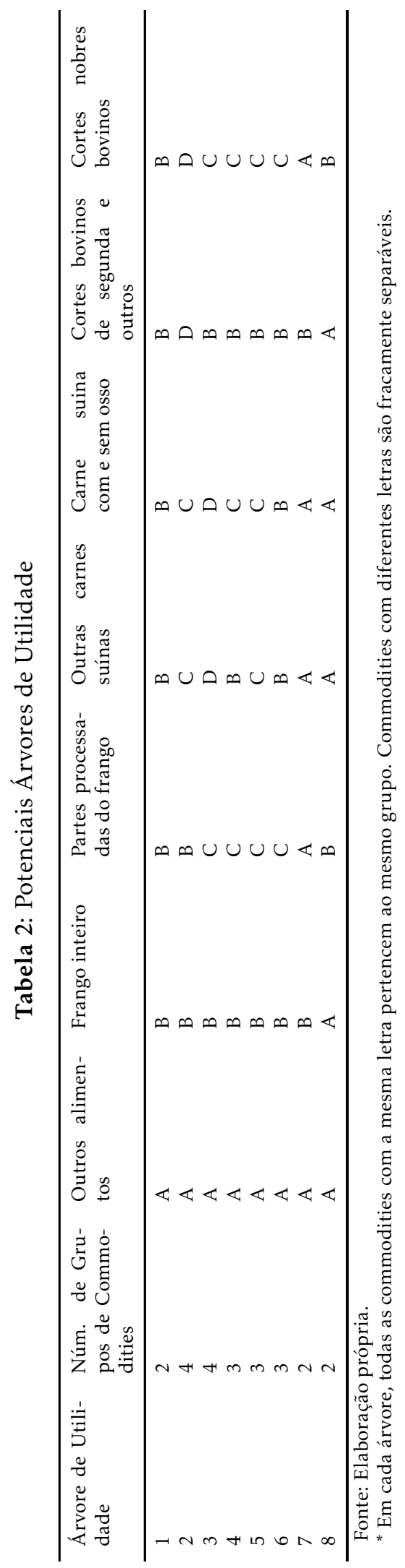


As informações utilizadas nesse estudo são provenientes dos microdados da Pesquisa de Orçamentos Familiares - POF (Pesquisa de Orçamentos Familiares: Aquisição domiciliar per capita 2010), sendo esta de caráter amostral, realizada pelo Instituto Brasileiro de Geografia e Estatística (IBGE), para os anos 2008/2009. Essa pesquisa foi realizada para uma amostra de 55970 domicílios, situados nas áreas urbanas e rurais de todo território brasileiro, disponibilizando informações sobre a composição orçamentária doméstica e sobre as condições de vida da população, visando mensurar as estruturas de consumo, dos gastos e fontes de rendimento. Além disso, a pesquisa mostra informações antropométricas, além do consumo e despesa individual (IBGE 2010).

Pelo fato de os microdados da POF apresentarem dados muito desagregados, com várias subdivisões por produto, foi necessário agregar os vários subtipos de Carnes de forma a se obter as categorias desejadas. Essa agregação foi obtida pela ponderação de cada subtipo pela parcela da despesa total do subtipo no produto correspondente para cada consumidor ${ }^{11}$. Isso permite captar de forma mais realista a participação dos subtipos mais "nobres" das carnes, em cada categoria pesquisada. Desse modo, as carnes considerados no sistema de demanda são apresentados na Tabela 3.

Já os outros alimentos considerados no sistema de demanda são apresentados na Tabela 4. Estes foram escolhidos de acordo com IBGE (2010) na seção do Anexo 2 - Composição dos grupos, subgrupos e produtos das tabelas de resultados. Foram agregados 36 grupos de alimentos para formar o grupo "Outros alimentos", de acordo com a ponderação de cada subtipo pela parcela da despesa total do subtipo no produto correspondente para cada consumidor. Desse modo, tal variável apenas refere-se a alimentos, excluindo qualquer tipo de bebida.

Dos 55970 domicílios entrevistados pela POF, 344 não informaram alguma das variáveis demográficas consideradas. Também foram retiradas 443 observações, cujos preços finais, obtidos após a estimação pelo procedimento de Cox e Wohlgenant (1986), possuíam valores muito elevados ou muito baixos ${ }^{12}$. Além disso, 5608 domicílios não apresentaram consumo de nenhum dos bens analisados e também foram retirados da amostra. Portanto, a amostra final possui 49575 observações, correspondente aos domicílios que declararam o consumo de pelo menos um dos bens (incluindo o bem residual).

Ao utilizar dados de pesquisas domiciliares com amostras complexas, como as Pesquisas de Orçamentos Familiares, é importante discutir como os procedimentos de amostragem podem afetar ou influenciar os resultados da pesquisa. Pesos amostrais são normalmente utilizados para resolver esse problema. Entretanto, tais pesos não foram incorporados nos procedimentos de estimação deste trabalho. Assim, como sugerido por Mutuc et al. (2007), é fornecida uma simples comparação de médias ( $\mathrm{t}$-test) para os dispêndios com os produtos analisados para mostrar a possível extensão do viés de amostragem. (Tabela A.2 no apêndice). Os resultados sugerem que parece haver diferença significativa entre as médias ponderadas e não ponderadas para seis dos sete dispêndios com os produtos analisados. Entretanto, ainda que existam dife-

\footnotetext{
${ }^{11} \mathrm{O}$ valor gasto e a quantidade adquirida de forma agregada foram encontrados por meio da soma dos valores gastos e quantidades com cada bem que compôs o grupo de interesse, respectivamente. O preço agregado foi encontrado por meio do somatório do valor gasto com cada bem em relação ao valor total gasto com o agregado multiplicado pelo preço de cada bem

${ }^{12}$ Por exemplo, carne bovina de primeira acima de $\mathrm{R} \$ 70 / \mathrm{Kg}$
} 
Tabela 3: Carnes utilizadas na estimação

\begin{tabular}{|c|c|}
\hline \multicolumn{2}{|c|}{ Carne Bovina } \\
\hline Cortes Nobres & Cortes de segunda e outro \\
\hline $\begin{array}{l}\text { Alcatra } \\
\text { Carne moída } \\
\text { Carne não esp. } \\
\text { Chã de dentro } \\
\text { Contrafilé } \\
\text { File-mignon } \\
\text { Lagarto comum } \\
\text { Lagarto redondo } \\
\text { Patinho }\end{array}$ & $\begin{array}{c}\text { Acém } \\
\text { Capa de filé } \\
\text { Carne moída } \\
\text { Carne não especificada } \\
\text { Costela } \\
\text { Músculo } \\
\text { Pá } \\
\text { Peito } \\
\text { Outras carnes de seg. } \\
\text { Carne hambúrguer } \\
\text { Carne de sol } \\
\text { Carne moída não esp. } \\
\text { Carne não especificada } \\
\text { Carne-seca } \\
\text { Mocotó } \\
\text { Outras }\end{array}$ \\
\hline \multicolumn{2}{|c|}{ Carne Suína } \\
\hline Com osso e sem osso & Outras carnes suínas \\
\hline $\begin{array}{l}\text { Carré } \\
\text { Costela } \\
\text { Lombo } \\
\text { Pernil } \\
\text { Porco eviscerado } \\
\text { Outras }\end{array}$ & $\begin{array}{c}\text { Carne salgada não esp. } \\
\text { Costela de porco salg. } \\
\text { Mortadela } \\
\text { Paio } \\
\text { Pé de porco salgado } \\
\text { Presunto } \\
\text { Salame } \\
\text { Salsicha comum } \\
\text { Toucinho fresco } \\
\text { Toucinho defumado } \\
\text { Outras }\end{array}$ \\
\hline \multicolumn{2}{|c|}{ Carne de Frango } \\
\hline Frango Processado & Frango Inteiro \\
\hline $\begin{array}{l}\text { Asa de frango } \\
\text { Carne de frango não esp. } \\
\text { Coxa de frango } \\
\text { Dorso do frango } \\
\text { Miúdos de frango } \\
\text { Peito de frango } \\
\text { Outras carnes de frango }\end{array}$ & $\begin{array}{c}\text { Frango abatido (inteiro) } \\
\text { Frango vivo }\end{array}$ \\
\hline
\end{tabular}

Fonte: Elaboração própria, a partir das informações POF (2008-2009) 
Tabela 4: Outros Alimentos utilizados na estimação

\begin{tabular}{lll}
\hline Cereais & Pães & Leite e creme de leite \\
Leguminosas & Bolos & Queijos e requeijões \\
Hortaliças folhosas & Biscoitos & Outros laticínios \\
Hortaliças frutosas & Carnes de outros animais & Açúcares \\
Hortaliças tuberosas e outras & Vísceras bovinas & Doces e produtos de confeitaria \\
Frutas de clima tropical & Vísceras suínas & Outros açúcares \\
Frutas de clima temperado & Outras vísceras & Sais \\
Cocos & Peixes de água doce & Condimentos \\
Castanhas e nozes & Peixes de água salgada & Óleos \\
Farinhas & Pescados não especificados & Gorduras \\
Féculas & Aves exceto frango & Alimentos preparados \\
Massas & Ovos & Outros alimentos \\
\hline
\end{tabular}

renças entre as médias, elas parecem ser pequenas, dando indícios de que os resultados não sofrem de grave viés de amostragem.

\section{Resultados e discussão}

\subsection{Teste de Separabilidade Fraca}

13

Os resultados do Teste de Máxima Verossimilhança para a separabilidade fraca são apresentados na Tabela 5. Examinando a tabela, todas as oito árvores de utilidade analisadas são rejeitadas para a hipótese de separabilidade fraca ao nível de significância de $1 \%$.

Tabela 5: Teste de Máxima Verossimilhança para as restrições de separabilidade fraca

\begin{tabular}{lcccccccc}
\hline Árvores & 1 & 2 & 3 & 4 & 5 & 6 & 7 & 8 \\
\hline Teste LR & 201,25 & 37,04 & 289,71 & 223,10 & 250,97 & 245,90 & 129,62 & 78,07 \\
Teste LR corrigido & 201,16 & 37,02 & 289,58 & 223,00 & 250,86 & 245,79 & 129,56 & 78,04 \\
Número de restrições & 5 & 14 & 14 & 13 & 12 & 12 & 9 & 9 \\
$\chi^{2}$ & 9,24 & 21,06 & 21,06 & 19,81 & 18,55 & 18,55 & 14,68 & 14,68 \\
$\chi^{2}$ & 11,07 & 23,68 & 23,68 & 22,36 & 21,03 & 21,03 & 16,92 & 16,92 \\
$\chi^{2}$ & 15,09 & 29,14 & 29,14 & 27,69 & 26,22 & 26,22 & 21,67 & 21,67 \\
\hline
\end{tabular}

Os resultados do teste de separabilidade fraca sugerem que os consumidores não alocam seu dispêndio separadamente entre carnes e outros alimentos. Desse modo, tal resultado confirma a necessidade de uma análise da demanda por carnes incluindo os demais alimentos no processo de decisão de alocação dos recursos pelos domicílios, incluindo o dispêndio com os mesmos. Além disso, confirmou-se que os consumidores não alocam seu dispêndio separadamente entre as carnes por tipo de animal ou por qualidade das carnes. Assim, tais resultados diferem dos alcançados por Eales \& Unnevehr (1988) para a demanda norte-americana por Carnes, em que, as mesmas foram separáveis

\footnotetext{
${ }^{13}$ Por questões de espaço, mostram-se aqui apenas os resultados dos testes de separabilidade fraca e as elasticidades estimadas. Os parâmetros estimados no primeiro e segundo estágio para o sistema de demanda estão disponíveis em Travassos (2014).
} 
dos demais alimentos, não sendo possível rejeitar a hipótese de que as carnes são separáveis entre agregados "mais nobres" e "menos nobres".

Portanto, tais resultados mostram que as hipóteses de que o grupo Carnes é fracamente separável do grupo de alimentos, sendo possível utilizar apenas preço e dispêndio com carnes para a estimação correta da demanda no grupo, e de que os segmentos do grupo carnes são fracamente separáveis por tipo de animal ou por qualidade da carne, são refutadas. Assim, o teste de separabilidade fraca confirma que estimar a demanda domiciliar por Carnes utilizando dados da POF 2008/2009 sem utilizar preço e dispêndio com Outros alimentos incorre em omissão de variáveis relevantes. Desse modo, o modelo a ser estimado para a análise das preferências por Carnes é o modelo irrestrito, incluindo preços e dispêndio com Outros Alimentos, tendo a árvore de utilidade o formato da 3.

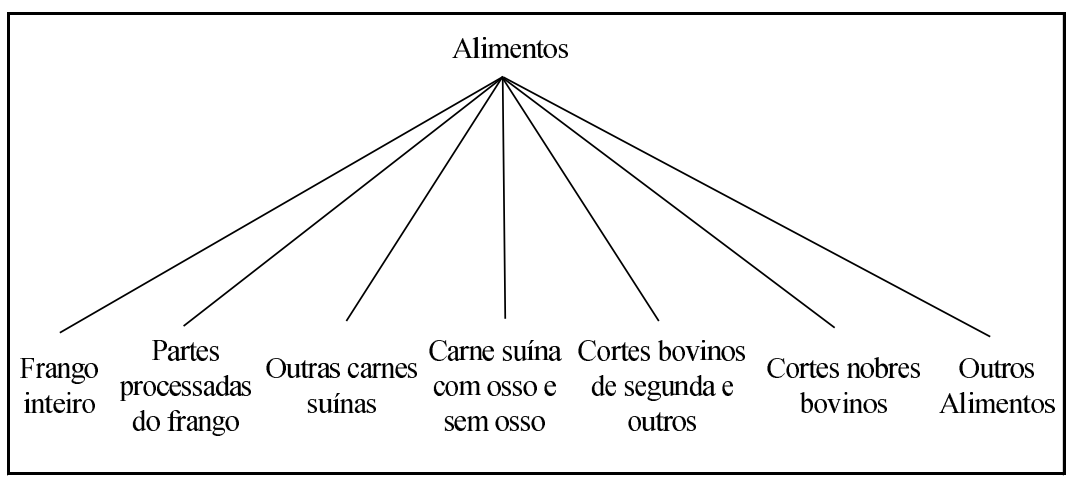

Fonte: Elaboração própria

Figura 3: Modelo irrestrito

\subsection{Comparação das elasticidades com diferentes árvores de utilidade}

O objetivo desta seção é mostrar os efeitos de não se testar previamente a separabilidade sobre as elasticidades estimadas. Se uma das oito árvores fosse escolhida a priori como representação da demanda brasileira por carnes, qual seria o efeito disso sobre as elasticidades? Quais seriam as diferenças em relação ao modelo irrestrito escolhido (e testado) neste trabalho? Assim, comparam-se a seguir as elasticidades-dispêndio $\left(e_{i}\right)$, preço próprias marshallianas $\left(e_{i i}^{u}\right)$ e preço cruzadas marshallianas $\left(e_{i j}^{u}\right)$ obtidas com a estimação dos sistemas de demanda que representam as oito árvores de utilidade examinadas neste estudo.

Além disso, serão apresentados os desvios padrões das respectivas elasticidades, calculadas pelo método delta, com o intuito de verificar se as elasticidades são estatisticamente diferentes entre os respectivos modelos.

A Tabela 6 apresenta as elasticidades-dispêndio dos respectivos modelos irrestrito e restritos. É possível verificar que, em todos os modelos, as elasticidadesdispêndio foram significativas ao nível de $1 \%$ de probabilidade e possuem sinais coerentes com a teoria da demanda. Além disso, pela análise dos desviospadrões das respectivas elasticidades-dispêndio nos diferentes modelos, é possível perceber que não há diferenças estatisticamente significativas entre as mesmas. Portanto, a não consideração da separabilidade fraca na estimação 
da demanda por carnes não interfere de forma significativa nas elasticidadesdispêndio.

Já a Tabela 7 apresenta a comparação das elasticidades-preço próprias marshallianas nos respectivos modelos. Com exceção das elasticidades do bem "Cortes bovinas de segunda e outros" em todos os modelos e de "Outros alimentos" nas árvores de utilidade 1, 3, 4 e 6, todas as demais elasticidades foram significativas ao nível de $1 \%$ de probabilidade. Além disso, pela análise dos desvios-padrões, é possível perceber que não há diferenças estatisticamente significativas entre as elasticidades-preço próprias marshallinas relacionadas às carnes, com exceção de alguns modelos para "Cortes nobres bovinos". No entanto, se analisadas as elasticidades e os desvios padrão de "Outros alimentos", é possível perceber que as restrições de separabilidade fraca afetam seus resultados. Portanto, a não consideração da separabilidade fraca ou dos demais alimentos na estimação da demanda por carnes não interfere de forma significativa nas elasticidades-preço próprias marshallinas da maioria das carnes, porém tem influência nas elasticidades de "Outros alimentos".

A Tabela 8 apresenta as principais mudanças em magnitude ou sinal nos resultados das elasticidades-preço cruzadas marshallianas ${ }^{14}$. No geral, percebese claramente que há, nesse caso, influência da hipótese de separabilidade fraca sobre as elasticidades-preço cruzadas. Pela análise dos desvios-padrões das elasticidades que foram significativas, no geral, há uma diferença estatisticamente significativa entre os modelos analisados. Isoladamente, algumas elasticidades-preço cruzadas de determinados bens são influenciadas em magnitude e sinal, como no caso das elasticidades-preço cruzadas do Frango inteiro em relação às Partes processadas do frango e Cortes nobres bovinos, por exemplo. Desse modo, infere-se que a hipótese de separabilidade fraca interfere de forma significativa nas elasticidades-preço cruzadas marshallianas das carnes.

Esses resultados são importantes na medida em que, como discutido na introdução, poderem afetar as análises de atos de concentração, como fusões e aquisições, que tem acontecido com frequência no setor de Carnes ${ }^{15}$. O tipo e grau de substituição entre os bens, como visto, depende da árvore de utilidade utilizada na estimação e a definição do mercado relevante também pode ser afetada por essa escolha. Assim, os resultados apontam a necessidade dos testes de Separabilidade para que as elasticidades-preço cruzadas obtidas sejam confiáveis e passiveis de serem utilizadas em outras aplicações.

\subsection{Implicações econômicas de diferentes hipóteses de separabilidade: análise de fusões}

16

Como forma de ilustrar a importância da análise de Separabilidade, esta seção mostra suas implicações na análise de fusões. Simulou-se uma fusão

\footnotetext{
${ }^{14}$ A tabela completa com as elasticidades-preço cruzadas encontra-se no Anexo na Tabela A.3.

${ }^{15}$ Em 2009 houve uma importante fusão no mercado de carnes brasileiro, entre as empresas JBS-Friboi e Bertin. Também em 2009 houve a compra da Seara, uma das maiores companhias de processamento de carnes de aves e suínos do país, pelo frigorífico Marfrig. Em 2013, a Seara foi vendida para a JBS. Sadia e Perdigão também tiveram sua fusão aprovada pelo CADE em 2011.

${ }^{16}$ Agradecemos ao parecerista anônimo da Revista por nos sugerir uma discussão das implicações econômicas da diferença nas elasticidades
} 


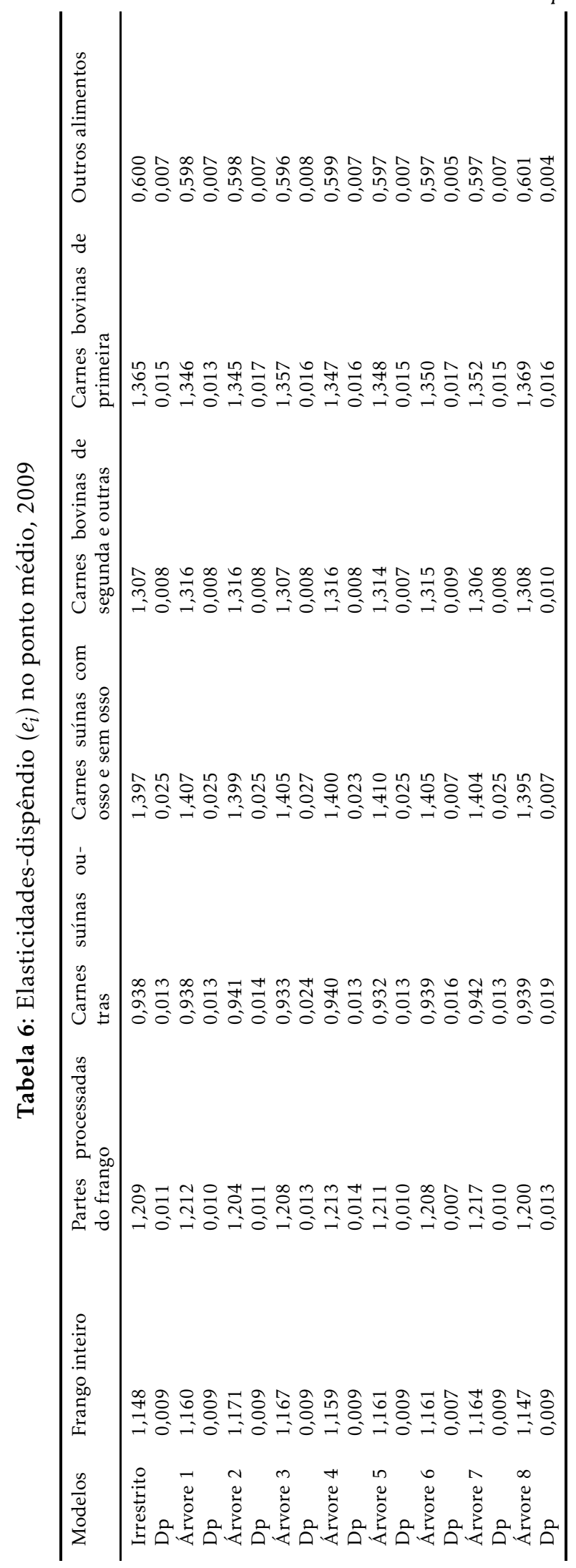




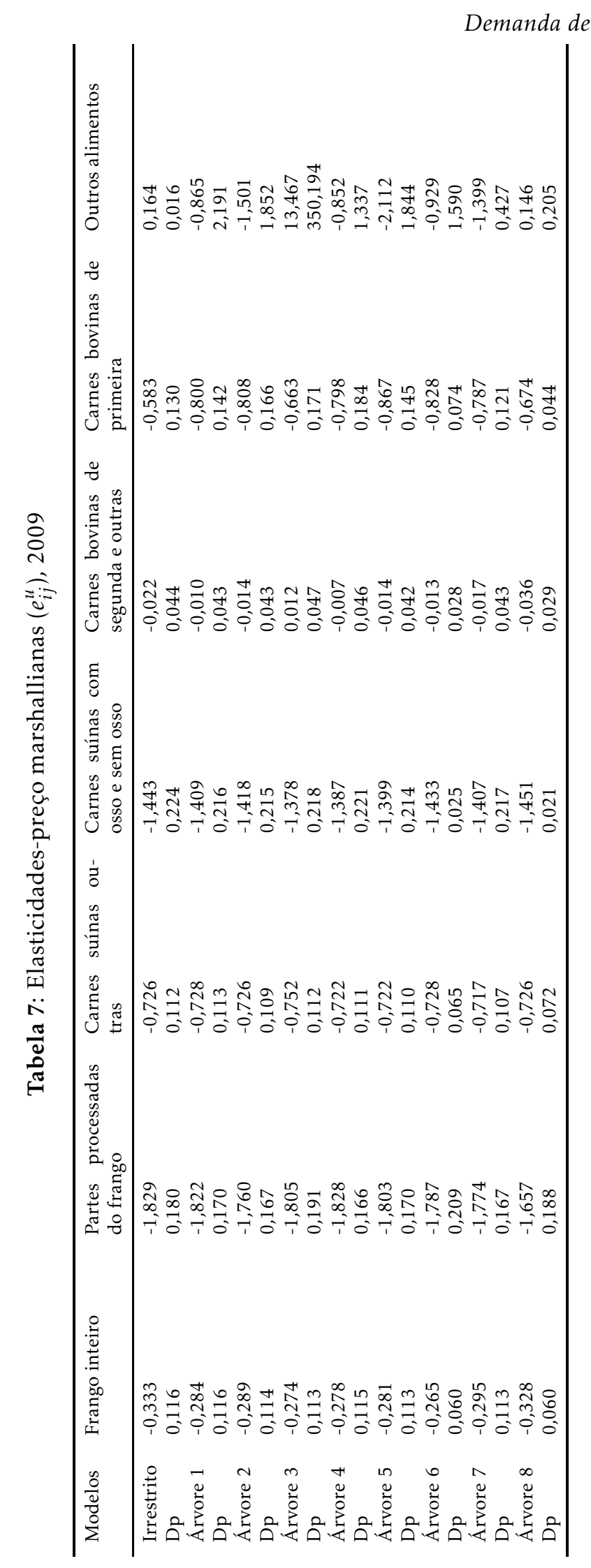




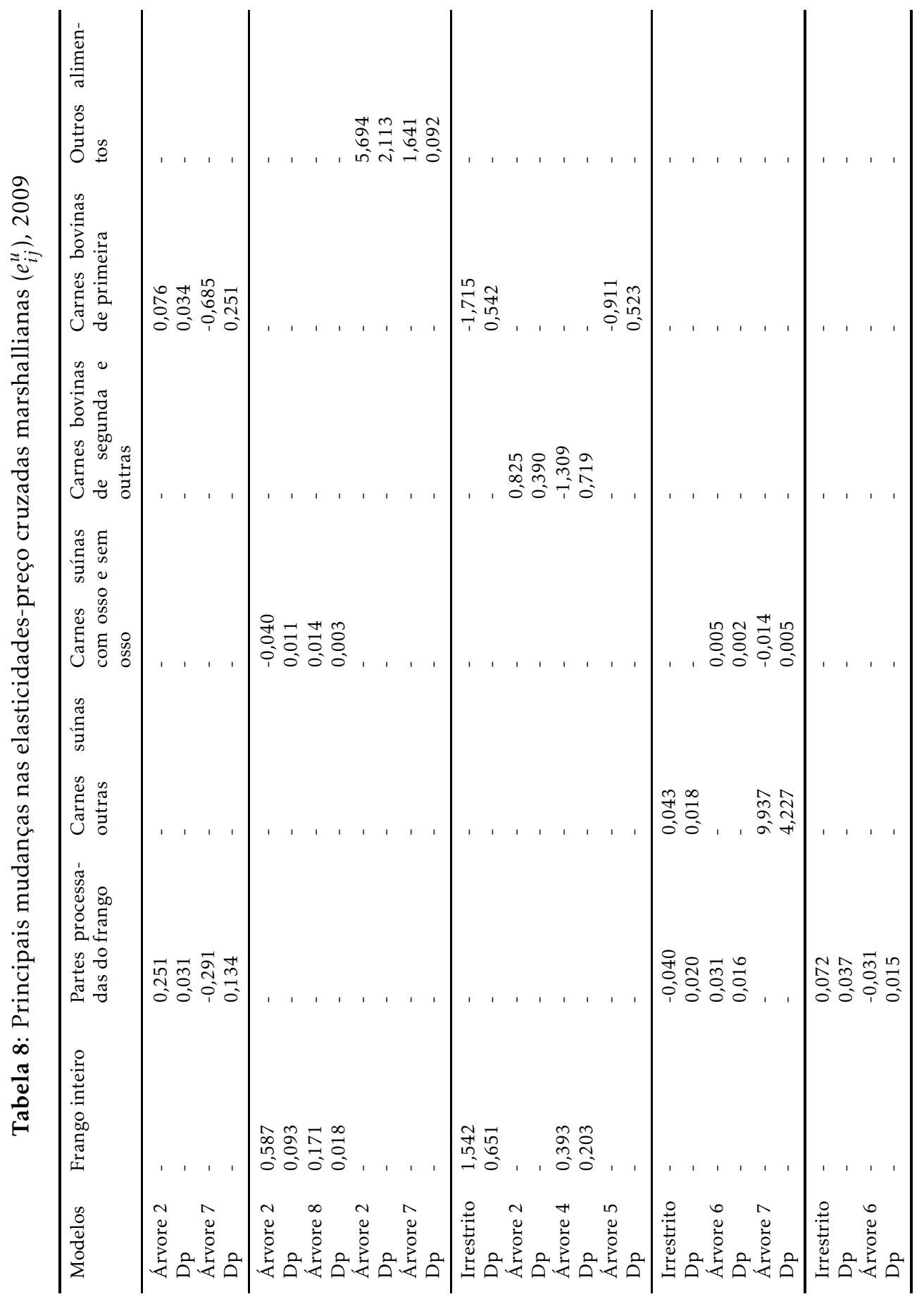


entre duas firmas hipotéticas do setor de Carnes, especificamente dos setores de processamento de partes de frango e de carne suína. Essa simulação segue a metodologia de Hausman et al. (1994) e é muito semelhante àquela feita por Huse \& Salvo (2006). A ideia aqui é entender como os efeitos unilaterais estimados de um ato de concentração de uma indústria de bens diferenciados podem diferir com a utilização de diferentes hipóteses sobre a separabilidade. Segundo Huse \& Salvo (2006), esse exercício consiste em duas etapas:

a) Estima-se o sistema de demanda a partir do equilíbrio pré-fusão, de forma a obter estimativas consistentes das elasticidades-preço próprias e cruzadas.

b) Assume-se um modelo comportamental e calcula-se, a partir do sistema de demanda estimado na primeira etapa, as elasticidades-preço e shares de valor para cada produto para o equilíbrio após a fusão. Efetua-se, então, o cálculo dos markups preço-custo utilizando as condições de primeira ordem do problema de maximização de lucro das firmas. Essas condições formam um sistema de $n$ equações (supondo $n$ firmas, cada uma com apenas 1 produto) que pode ser expresso como ${ }^{17}$ :

$$
s(p)=E(p)^{\prime} \omega=0,
$$

em que $s(p)$ é um vetor de dimensão $n \times 1$ de shares de valor dos produtos, $E(p)$ é uma matriz de dimensão $n \times n$ de elasticidades-preço e $\omega$ é um vetor de dimensão $n \times 1$ referente aos markups de preço-custo multiplicados pelos shares de valor. A solução desse sistema passa pela inversão da (transposta) da matriz de elasticidades $(E(p))$, de forma a obter o vetor de markup $\times$ share de valor $\omega$, conforme segue (Huse \& Salvo 2006), pg. 33):

$$
\omega=-\left(E(p)^{\prime}\right)^{-1} s(p)
$$

Os markups pós-fusão $\left(\theta_{i}^{M}\right)$ podem ser calculados a partir da divisão elementopor-elemento do vetor de markup $\times$ share de valor $\omega$ por $s(p)$, ou seja:

$$
\theta_{i}^{M}=\frac{p_{i}^{M}-c_{i}}{p_{i}^{M}}=\frac{\omega_{i}}{s_{i}(p)}
$$

em que $p_{i}^{M}$ é o preço pós-fusão do produto $i$ e $c_{i}$ é o custo marginal pósfusão ${ }^{18}$.

Os cálculos das variações de preço pós-fusão podem ser feitos da seguinte forma (Hausman et al. 1994, p. 176):

$$
\frac{p_{i}^{M}-p_{i}}{p_{i}}=\frac{1}{\left(\frac{e_{i i}}{1+e_{i i}}\right)\left(1-\theta_{i}^{M}\right)}
$$

Em que $p_{i}$ é o preço pré-fusão do produto $i$ e $e_{i i}$ é a elasticidade-preço própria do produto $i$.

\footnotetext{
${ }^{17}$ Para uma derivação completa desse modelo, ver Huse \& Salvo (2006), pags. 2733

${ }^{18}$ Supõe-se, para simplificar, que não há ganhos de eficiência com a fusão, de forma que os custos marginais pré e pós fusão são iguais.
} 
A parte (a) foi realizada anteriormente para as 8 árvores de utilidade e para o modelo irrestrito ${ }^{19}$. Quanto ao item (b), supõe-se um modelo de conduta Nash-Bertrand e que as elasticidades e shares pós-fusão são os mesmos da situação pré-fusão. Esta última hipótese simplificadora também foi usada por Huse \& Salvo (2006). Supõe-se também shares (de valor) de mercado de $20 \%$ para a empresa processadora de frango e $10 \%$ para a empresa processadora de suínos, de forma que a firma pós-fusão teria um share de $30 \%$. Os resultados da simulação de fusão usando o modelo irrestrito e as 8 árvores de utilidade, que refletem diferentes hipóteses sobre a separabilidade, estão na Tabela 9.

Pode-se notar como as estimativas dos markups e mudanças de preço variam consideravelmente com as diferentes hipóteses de Separabilidade. Por exemplo, ao considerar que as partes processadas de frango e a carne suína com e sem osso estão no mesmo subgrupo de "carnes de primeira" (Arvore 4), as estimativas sobre o markup e variações de preço pós fusão são bem diferentes do modelo irrestrito para a firma processadora de frango. Enquanto para o modelo irrestrito a simulação prevê uma diminuição do markup (de 54,67\% para $49,53 \%)$ e do preço pós-fusão $(-10,19 \%)$, para a árvore 4 a previsão é de aumento de preços $(2,28 \%)$ e do markup. Essa discrepância é explicada pela diferença nas elasticidades-preço cruzadas nas duas árvores examinadas: enquanto no modelo irrestrito há uma relação de complementariedade entre carne suína com osso e sem osso e partes processadas de frango $\left(e_{i j}=-0,266\right)$, fazendo com que uma redução no preço do frango cause um aumento na demanda de carne suína, na árvore 4 temos uma relação de substituição entre esses grupos, fazendo com que a fusão signifique uma atenuação da concorrência e permitindo um aumento de preços das partes processadas de frango. Esse tipo de diferença também é observada no caso da carne suína: para a árvore 2 (árvore em que os consumidores escolhem as carnes por tipo de animal), a única em que a elasticidade-preço cruzada entre carne suína e preço de partes processadas de carne de frango é negativa, as estimativas de mudanças de preço $(-9,41 \%$ ) e de markups (de 70,52\% para 67,46\%) tem sinais contrários às outras especificações, em que esses produtos são considerados substitutos.

Assim, mesmo que as elasticidades-preço cruzadas sejam apenas um pouco diferentes sob diferentes hipóteses de Separabilidade, as simulações mostram diferenças importantes nos efeitos simulados de uma fusão. A Separabilidade, ao impor restrições sobre o padrão de substituições de produtos de grupos diferentes, modifica as conclusões sobre os efeitos esperados de uma fusão. Um órgão antitruste, ao pressupor uma determinada árvore de utilidade sem testar a separabilidade, poderia decidir aceitar ou rejeitar uma fusão (ou impor medidas restritivas, como venda de ativos) baseado em estimativas de mudanças de preços que poderiam estar equivocadas.

\section{Conlusões}

O presente estudo buscou testar a separabilidade fraca em um sistema de demanda por carnes no Brasil, hipótese frequentemente assumida em análises

\footnotetext{
${ }^{19}$ Há, é claro, uma hipótese simplificadora aqui ao se utilizar as estimativas das elasticidadespreço dos produtos calculadas anteriormente como se fossem elasticidades das firmas hipotéticas. Como a intenção aqui é apenas entender como o uso de diferentes hipóteses de Separabilidade afetam os efeitos esperados da fusão, esta simplificação não afeta as conclusões da simulação, apesar de afetar os níveis dos markups estimados, que serão naturalmente mais altos (pois as elasticidades-preço próprias são menores em módulo) do que se poderia esperar.
} 


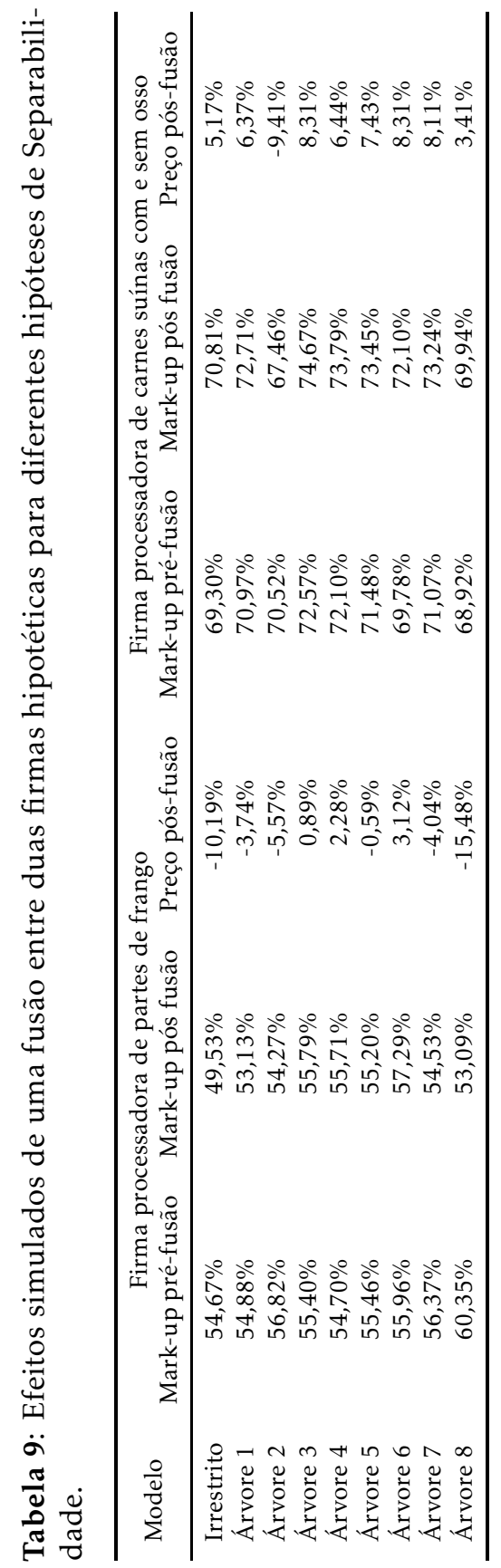


de demanda aplicada, sendo condição para representar o consumo em estágios de orçamento, em que se utiliza apenas preço e dispêndio do bem separável na estimação de demanda e, ainda, pode reduzir consideravelmente a quantidade de parâmetros na estimação. Desse modo, a principal contribuição deste estudo para a literatura nacional foi quanto à utilização do conceito de separabilidade fraca na estimação da demanda por carnes no Brasil, verificando o formato estatisticamente adequado da árvore de utilidade para a demanda por carnes no Brasil.

Depois de testadas as restrições de separabilidade fraca para oito árvores de utilidade, baseadas na intuição econômica e nos dados disponíveis, utilizando o Teste de Máxima Verossimilhança com a correção de tamanho proposto por Italianer (1985), verificou-se que o grupo Carnes não é separável dos demais alimentos, e que não há separabilidade fraca entre as carnes por tipo de animal ou por qualidade. Assim, a árvore de utilidade escolhida como adequada foi o modelo irrestrito, em que todos os alimentos são demandados em um mesmo estágio de consumo. Portanto, constatou-se que os consumidores não separam carnes por tipo de animal ou por qualidade da mesma e que, para uma estimação correta de um sistema de demanda por carnes utilizando dados da POF 2008/2009, é necessário incluir preços e dispêndio com todos os alimentos na estimação. Assim, o teste de separabilidade fraca confirma que estimar a demanda domiciliar por Carnes utilizando dados da POF 2008/2009 sem utilizar preço e dispêndio com Outros alimentos incorre em omissão de variáveis relevantes.

Verificou-se ainda que, ao se estimar sistemas de demanda não considerando a hipótese de separabilidade fraca, não se encontram diferenças estatisticamente significativas nas elasticidades-dispêndio e nas elasticidades-preço marshallianas para a grande maioria das carnes analisadas. Porém, perceberamse diferenças estatisticamente significativas nas elasticidades-preço cruzadas. Desse modo, a escolha de determinada árvore de utilidade em detrimento aos demais modelos pode influenciar nas interpretações dos resultados, principalmente nas relações de substitubilidade e complementariedade entre os bens em análise. As implicações de não se considerar a separabilidade fraca ficam claras na simulação de uma fusão entre empresas do setor de carnes, em que as diferenças nas elasticidades-preço cruzadas causam grandes modificações nos efeitos esperados sobre preços e markups.

\section{Referências Bibliográficas}

Afriat, S. (1967), The construction of separable utility functions from expenditure data.

An Almost Ideal Demand System (1980), The American Economic Review 70(3).

Banks, J., Blundell, R. \& Lewbel, A. (1997), 'Quadratic engel curves and consumer demand', The Review of Economics and Statistics LXXIX(LXXIX), 527539.

Blackorby, C., Primont, D. \& Russel, R. R. (1978), 'Duality, separability and functional structure: Theory and economic applications', New York: American Elsevier . 
Blundell, R. \& Robin, J. M. (1999), 'Estimation in large and disaggregated demand systems: An estimator for conditionally linear systems', Journal of Applied Econometrics 14, 14.

Byron, R. P. A. (1970), 'Simple method for estimating demand systems under separable utility assumptions', The Review of Economic Studies 37(37), 261274.

Coelho, A. B., Aguiar, D. R. D. \& Eales, J. S. (2010), 'Food demand in Brazil: an application of shonkwiler and yen two-step estimation method', Estudos Econômicos 40(1), 186-211. São Paulo: USP.

Cox, T. L. \& Wohlgenant, M. K. (1986), 'Prices and quality effects in cross-sectional demand analysis', American Journal of Agricultural Economics 68(4), 908-919.

Deaton, A. (1988), 'Quality, quantity and spatial variation of prices', The American Economic Review 78(3), 418-430.

Deaton, A. \& Muellbauer, J. (1980), 'Economics and consumer behavior', New York: Cambridge p. 450.

DEE, D. D. E. E. (2010), 'Delimitação de mercado relevante — versão pública'. Acesso em: 10 de novembro de 2014.

URL: $h t t p: / / w w w . c a d e . g o v . b r / u p l o a d / D e l i m i t a c a o \_d e \_m e r c a d o \_r e l e v a n t e . p d f$

Denny, M. \& Fuss, M. (1977), 'The use of approximation analysis to test forseparability and the existence of consistent aggregates', The American Economic Review 67(3), 404-418.

Eales, J. S. \& Unnevehr, L. J. (1988), 'Demand for beef and chicken products: Separability and structural change', American Journal of Agricultural Economics 70, 521-32.

Eales, J. S. \& Wessels, C. R. (1999), 'Testing separability of japanese demand for meat and fish within differentiated demand systems', Journal of Agricultural and Resources Economics 24, 114-26.

Gorman, W. M. (1981), Some Engel Curves in Essays in theory and measurement of consumer behavior: in honour of Sir Richard Stone, Angus Deaton, Cambridge, UK. $384 \mathrm{p}$.

Greene, W. H. (2008), Econometric analysis, 6 edn, Prentice Hall.

Hausman, J. A., Leonard, G. K. \& Zona, J. D. (1994), 'Competitive analysis with differentiated products', Annales D'Economie et de Statistique 34, 159180 .

Huse, C. \& Salvo, A. (2006), Estimação e identificação de demanda e de oferta, Vol. Métodos Quantitativos em Defesa da Concorrência e Regulação Econômica, IPEA.

IBGE, I. B. D. G. E. E. (2010), 'Microdados da POF 2008-2009 (Pesquisa de Orçamentos Familiares)', CD-Rom. Rio de Janeiro. 
Italianer, A. (1985), 'A small-sample correction for the likelihood ratio test', Econ. Letters 19(4), 315-317.

Jorgenson, D. W. \& Lau, L. J. (1975), 'The structure of consumer preferences', Ann. Econ. and Soc. Measure. 70(3), 312-326.

Lafrance, J. T. (1991), 'When is expenditure "exogenous" in separable demand models?', Western Journal of Agricultural Economics 16(1), 49-62.

Lambert, R., Larue, B., Yelo, C. \& Criner, G. (2006), 'Fish and meat demand in Canada: Regional diferences and weak separability', Agribusiness 22, 175199.

Leontief, W. W. (1947), 'Introduction to the theory of the internal structure of functional relationships', Econometrica 5(36), 1-73.

Meisner, J. F. (1979), 'The sad fate of the asymptotic slutsky symmetry: Test for large systems', Econ. Letters. 2(23), 1-33.

Moschini, G., Moro, D. \& Green, R. D. (1994), 'Maintaining and testing separability in demand system', American Journal of Agricultural Economics 76, 61-73.

Mutuc, M. E. M., Pan, S. \& Rejesus, R. M. (2007), 'Household vegetable demand in the Philippines: Is there an urban-rural divide?', Agribusiness 23(4), 511-527.

Njonou, R. Y., De Frahan, B. H. \& Surry, Y. (2002), Testing separability for common wheat qualities in French import demand market using aids and Rotterdam demand models, in 'Xth EAAE Congress Exploring Diversity in the European Agri-Food System,', Zaragoza (Spain).

Pesquisa de Orçamentos Familiares: Aquisição domiciliar per capita (2010), Rio de Janeiro .

Pudney, S. (1981), 'An empirical method of approximating the separable structure of consumer preferences', Rev. Econ. Stud. 48, 561-77.

Resende Filho, M. A., Bressan, V. G. F., Braga, M. J. \& Bressan, A. A. (2012), 'Sistemas de equações de demanda por carnes no brasil: especificação e estimação', Revista de Economia e Sociologia Rural 50(1), 33-50.

Rodrigues, C. T., Coelho, A. B. B., Braga, M. J. \& Gomes, A. P. (2012), 'Demanda por nutrientes nas principais regiões metropolitanas do Brasil no período de 1995-2003', Economia Aplicada 16(1).

Sono, M. (1961), 'The effect of price changes on the demand and supply of separable goods', Int. Econ. Rev. 2, 239-71.

Swofford, J. L. \& Whitney, G. A. (1987), 'Nonparametric tests of utility maximization and weak separability for consumption, leisure and money', Rev Econ. and Statist. 69, 458-64.

Travassos, G. F. (2014), Demanda domiciliar por carnes no Brasil: A questão da separabilidade, Dissertação (mestrado em economia aplicada), Universidade Federal de Viçosa - UFV. 


\section{Apêndice A}

Tabela A.1: Estatística descritivas das variáveis, 2009

\begin{tabular}{lcccc}
\hline Produtos & Média & Desvio-padrão & \multicolumn{2}{c}{ Intervalo de Confiança } \\
\hline$w 1$ & 0,052 & 0,001 & 0,051 & 0,053 \\
$w 2$ & 0,021 & 0,000 & 0,021 & 0,022 \\
$w 3$ & 0,019 & 0,000 & 0,019 & 0,020 \\
$w 4$ & 0,013 & 0,000 & 0,012 & 0,013 \\
$w 5$ & 0,094 & 0,001 & 0,092 & 0,095 \\
$w 6$ & 0,054 & 0,001 & 0,053 & 0,056 \\
$w 7$ & 0,746 & 0,001 & 0,744 & 0,748 \\
$\ln p 1$ & 1,508 & 0,001 & 1,507 & 1,509 \\
$\ln p 2$ & 1,702 & 0,001 & 1,701 & 1,703 \\
$\ln p 3$ & 1,982 & 0,001 & 1,979 & 1,984 \\
$\ln p 4$ & 1,909 & 0,001 & 1,907 & 1,911 \\
$\ln p 5$ & 2,053 & 0,001 & 2,051 & 2,055 \\
$\ln p 6$ & 2,351 & 0,001 & 2,350 & 2,353 \\
$\ln p 7$ & 1,468 & 0,002 & 1,463 & 1,472 \\
$\ln$-dispêndio (alimentos) & 3,654 & 0,003 & 3,649 & 3,659 \\
$\ln$ dispêndio (carnes) & 1,899 & 0,002 & 1,894 & 1,903 \\
Urbano & 0,773 & 0,002 & 0,769 & 0,776 \\
Norte & 0,143 & 0,002 & 0,140 & 0,146 \\
Nordeste & 0,362 & 0,002 & 0,358 & 0,366 \\
Sul & 0,119 & 0,001 & 0,116 & 0,122 \\
Sudeste & 0,240 & 0,002 & 0,236 & 0,244 \\
Centro-Oeste & 0,136 & 0,002 & 0,133 & 0,139 \\
Anos de estudo & 6,228 & 0,021 & 6,187 & 6,268 \\
Mulher chefe & 0,303 & 0,002 & 0,299 & 0,307 \\
Criança & 0,451 & 0,002 & 0,446 & 0,455 \\
Adolescente & 0,293 & 0,002 & 0,289 & 0,297 \\
Idoso & 0,230 & 0,002 & 0,226 & 0,234 \\
\hline
\end{tabular}

Tabela A.2: Comparação de médias dos gastos com produtos, com e sem peso amostral, 2009

\begin{tabular}{lcccc}
\hline Produtos & Média com peso & Média sem peso & Diferença & p-value \\
\hline Frango inteiro & 3,071 & 2,414 & $-0,657$ & 0,000 \\
Partes processadas do frango & 1,732 & 1,447 & $-0,285$ & 0,000 \\
Carnes suínas outras & 1,444 & 1,179 & $-0,265$ & 0,000 \\
Carnes suínas com e sem osso & 1,059 & 1,107 & 0,049 & 0,257 \\
Carnes bovinas de segunda e outras & 5,729 & 6,217 & 0,488 & 0,000 \\
Carnes bovinas de primeira & 4,511 & 4,314 & $-0,197$ & 0,000 \\
Outros alimentos & 45,980 & 44,839 & $-1,141$ & 0,000 \\
\hline
\end{tabular}




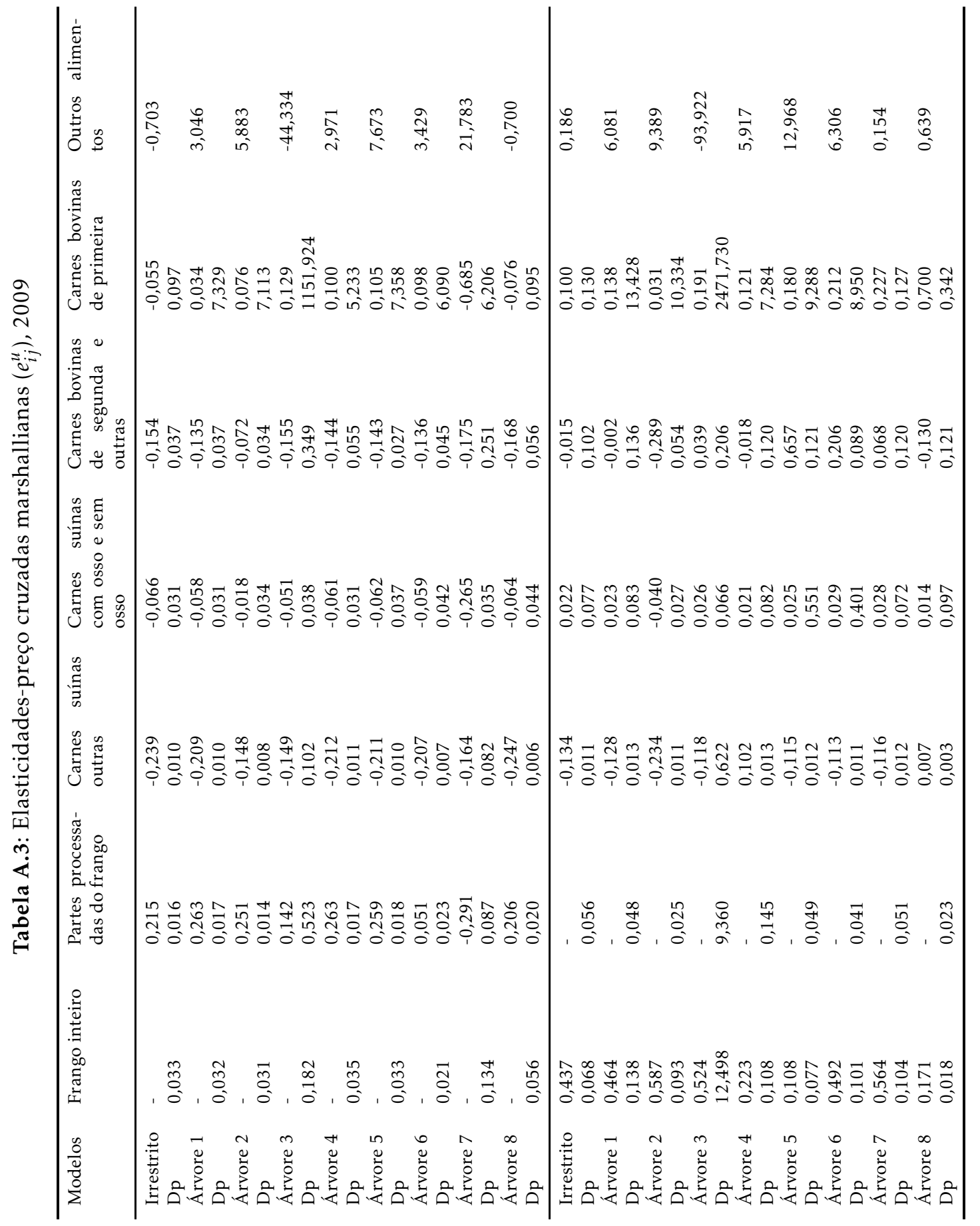




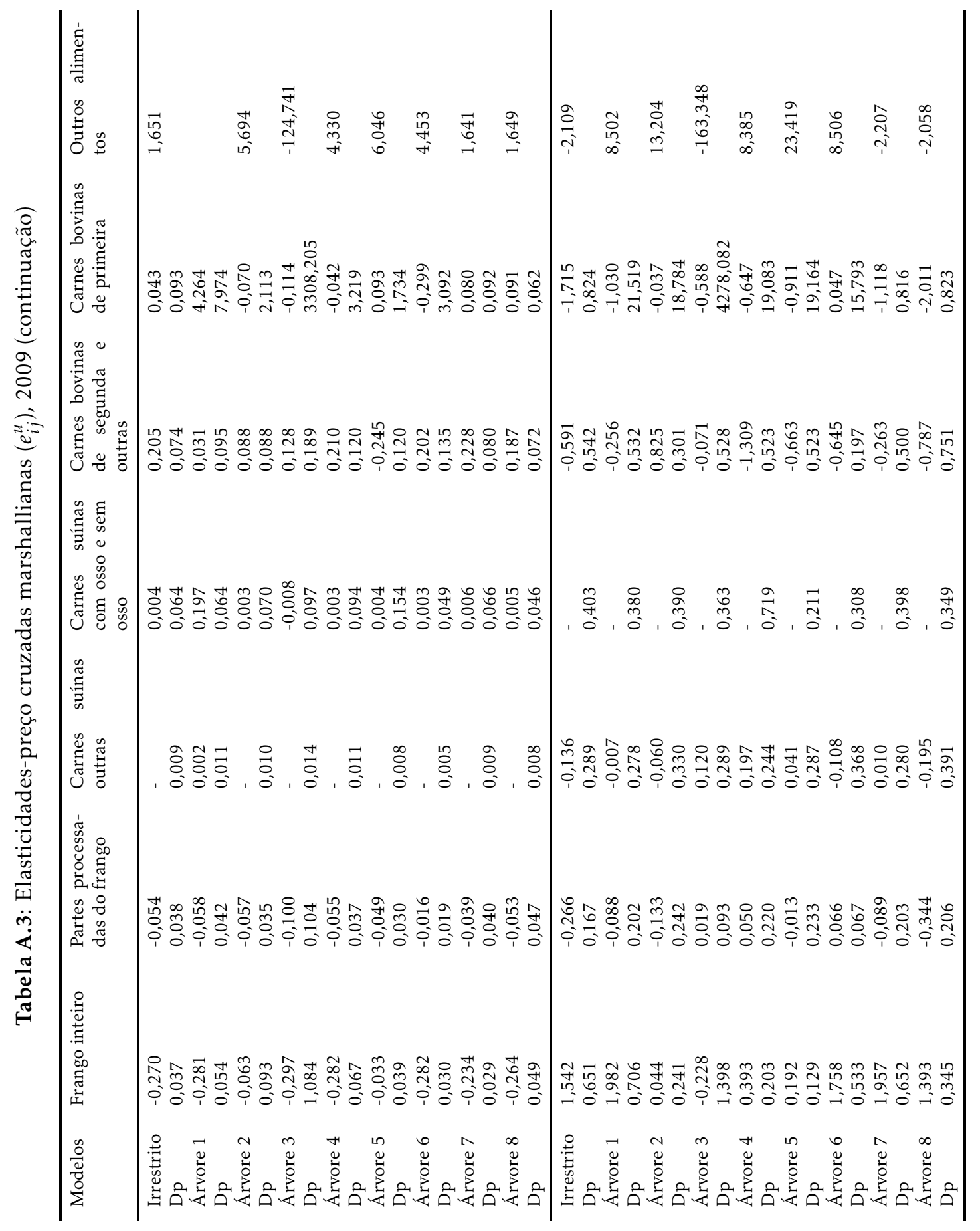




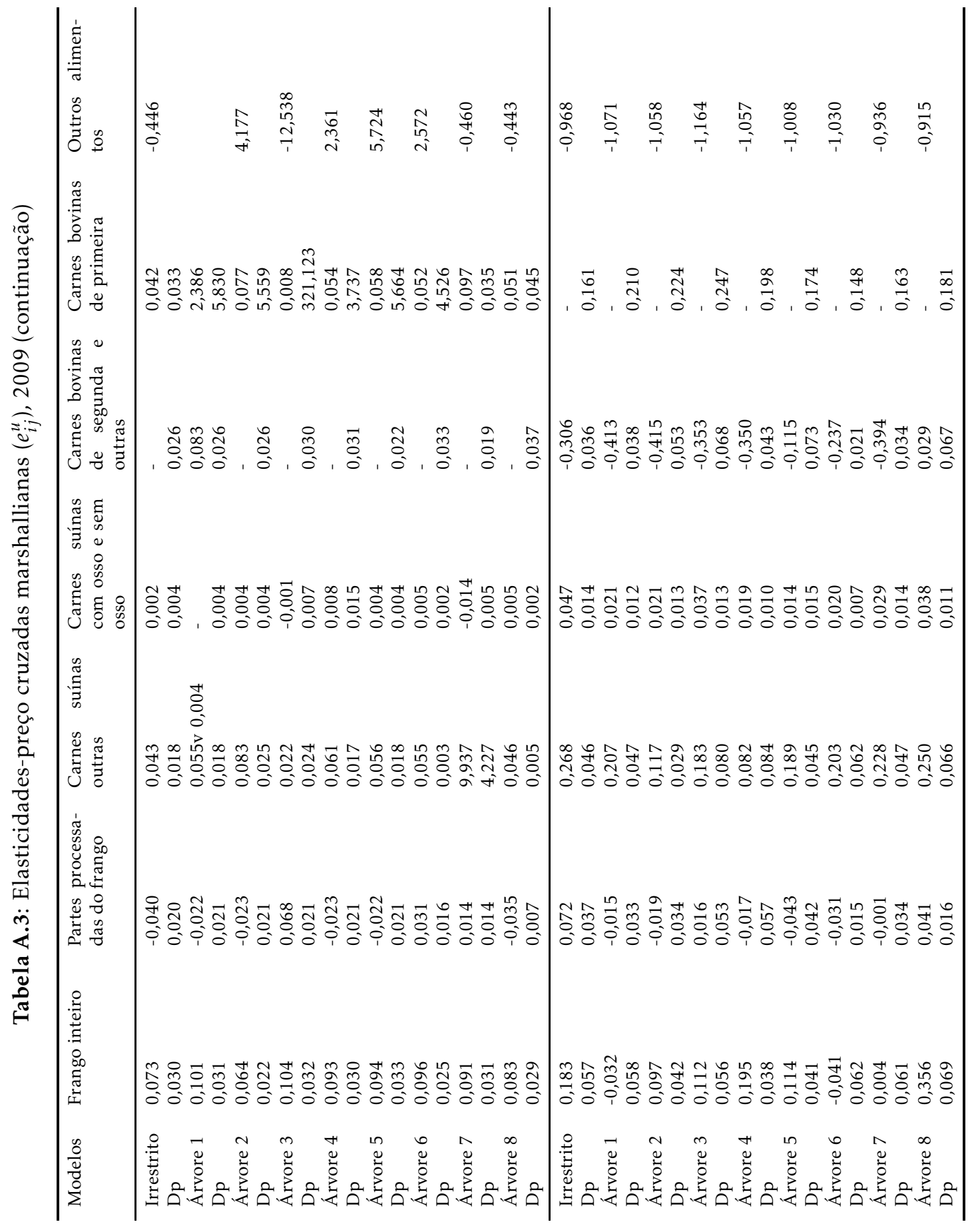




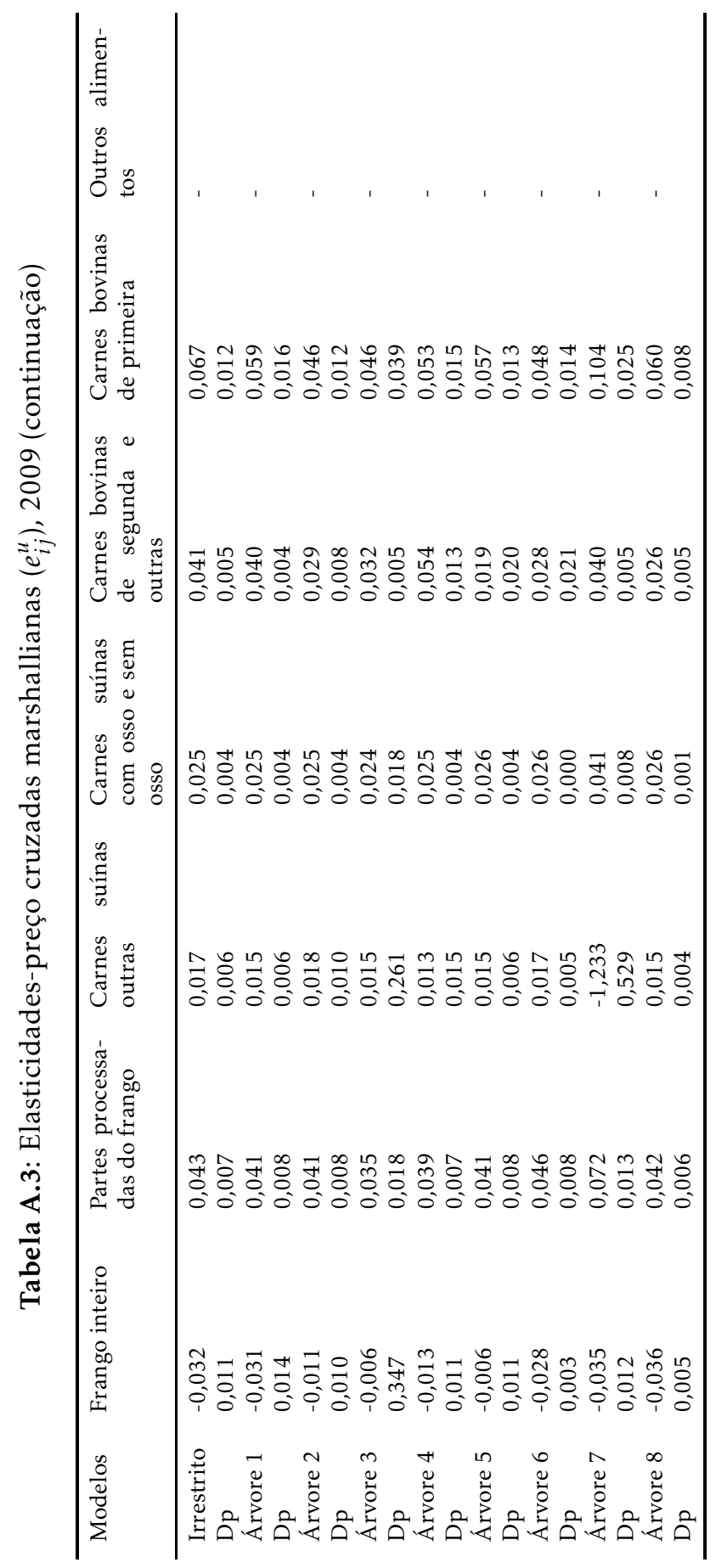

